\title{
Cotas e desempenho na Universidade Federal da Bahia: uma análise dos ingressantes de 2010 a 2012
}

\author{
Juliana Lago dos Santos ${ }^{1}$ \\ Cláudia Malbouisson² \\ Vinicius Felipe da Silva ${ }^{3}$ \\ Ivanessa Thaiane do Nascimento Cavalcanti ${ }^{4}$
}

\begin{abstract}
Resumo: A discussão acerca do impacto das ações afirmativas sobre o desempenho acadêmico dos alunos no ensino superior tem recebido cada vez mais atenção na literatura, principalmente quando considerados os problemas na formação básica de boa parte desses estudantes. O objetivo deste trabalho é verificar se existe diferencial de desempenho acadêmico entre os estudantes da UFBA que ingressaram nos anos 2010, 2011 e 2012, por categoria de ingresso e área de conhecimento. Aplicou-se o método dos Mínimos Quadrados Ordinários para estimar o impacto de ser cotista sobre o coeficiente de rendimento em comparação aos estudantes não cotistas. Os resultados indicam diferenciais a favor dos estudantes não cotistas em quase todas as áreas de conhecimento.
\end{abstract}

Palavras-chave: Ensino Superior, Ações Afirmativas, Desempenho acadêmico, Cotas.

Classificação JEL: I20, I23, I28, J15

Quotas and perfomance at federal university of bahia: an analysis of the 2010 to 2012 entrants

\begin{abstract}
The discussion around the impact of affirmative action on students' academic performance in higher education has been receiving an increasing amount of attention in the literature, mainly when considering the problems in basic education experienced by a large part of these students. This work aims to assess differences in academic performance between students from UFBA who entered the university in the years 2010, 2011 and. We used the method of OLS to estimate the impact of being included in the quota on the grade point average, in comparison to the non-quota
\end{abstract}

1 Mestranda em Economia pela Universidade Federal da Bahia. E-mail: julianalagosan@gmail.com

2 Doutora em Economia pela Universidade Federal da Bahia. Professora Adjunta do Departamento de Economia da Universidade Federal da Bahia e pesquisadora do Grupo de Pesquisas em Economia Aplicada. E-mail: cmalbo@ufba.br.

3 Doutorando em Economia pela Universidade Federal de Pernambuco. Companhia Hidro Elétrica do São Francisco. E-mail: vfelipedasilva@gmail.com.

4 Doutora em Economia pela Universidade Federal da Bahia. E-mail: ivanessatnc@gmail.com 
students. The results indicate differences in favor of non-quota students in almost all knowledge areas.

Keywords: Higher Education, Affirmative Action, Academic Performance, Quotas.

\section{Introdução}

Diversos países ao redor do mundo aplicam alguma política de ações afirmativas na educação como forma de garantir o acesso de grupos da sociedade que tenham sido mantidos historicamente a parte do processo de formação de capital humano da sociedade. No Brasil a política de ações afirmativas na educação tem início anos 2000 com objetivo de reduzir a desigualdade entre os grupos da sociedade e também como forma de resgate histórico das minorias à margem do processo educacional.

Os efeitos da política de ações afirmativas têm sido discutidos de forma crescente na iliteratura e sob diferentes aspectos. De acordo com Bertrand et al. (2010), o debate está centrado em duas questões principais: alcance e efeitos da política. A primeira trata a questão de quem estes programas realmente atingem, ou seja, se o público alvo das ações afirmativas são os verdadeiros beneficiários. A segunda questão é se esses programas realmente ajudam aqueles que têm acesso a universidade somente na condição de beneficiários do programa.

Os defensores das ações afirmativas argumentam que tais políticas podem resultar em ganhos líquidos para os grupos desfavorecidos e para a sociedade. De acordo com Arcidiacono et al. (2011), os favoráveis às ações afirmativas argumentam que admissões na universidade baseada nessas ações são importantes tanto para ajudar minorias a superar o legado da discriminação institucionalizada, quanto para os estudantes majoritários que recebem benefícios da diversidade inter-racial nas turmas.

No Brasil, a Lei $n^{\circ} 12.711 / 2012$, sancionada em agosto de 2012, mudou o panorama do sistema de reserva de vagas nas universidades tornando obrigatória a adoção do sistema por todas as Instituições Federais de Ensino Superior (IFES), englobando um total de 59 universidades federais e 38 institutos federais de educação ciência e tecnologia. A lei determina que $50 \%$ das matrículas das universidades e institutos federais sejam destinadas a alunos que frequentaram o ensino médio em colégios públicos e a outra metade a ampla concorrência. A Universidade Federal da Bahia (UFBA), que desde 2005 utilizava em seu sistema de ingresso reserva de vagas, adotou a "Lei de Cotas" já para os ingressos no vestibular de 2013.

A despeito da relevância e da crescente discussão sobre o tema, a literatura sobre os efeitos das ações afirmativas no Brasil ainda é bastante reduzida. Este trabalho enquadra-se nessa temática e busca analisar se existe diferencial de de- 
sempenho acadêmico entre alunos beneficiários do sistema de reserva de vagas e os demais na Universidade Federal da Bahia por grandes áreas de conhecimento. Para tanto foram considerados todos os alunos ingressantes por vestibular matriculados nos anos de 2010, 2011 e 2012. Os dados são provenientes do Sistema Acadêmico da UFBA e do questionário socioeconômico respondido pelos candidatos no momento da inscrição no vestibular e a análise foi feita por Mínimos Quadrados Ordinários.

Além dessa introdução, mais três seções ajudarão no desenvolvimento deste trabalho. $\mathrm{Na}$ segunda seção é trazida uma breve apresentação das políticas de ações afirmativas para o ensino superior, uma breve revisão da literatura e como a Universidade Federal da Bahia, objeto de estudo deste artigo, adotou a política de cotas na seleção de entrada de novos estudantes. A terceira seção apresenta a descrição dos dados utilizados, metodologia, variáveis e resultados encontrados com as estimações. Na última seção são apresentadas as considerações finais.

\section{Ações Afirmativas}

De acordo com o GEMAA (2013), ações afirmativas consistem em uma forma de alocar recursos para grupos excluídos, discriminados e/ou vitimados devido a características socioeconômicas, questões étnicas, raciais, religiosas, de gênero ou de castas no passado ou presente. Basicamente, Políticas de Ações Afirmativas referem-se ao conjunto de medidas que garantem a participação desses grupos no acesso a serviços básicos como educação, saúde, emprego e processo político (GEMAA, 2013).

Para Silva Filho e Cunha (2013) as ações afirmativas podem ser compreendidas como ações compensatórias e que buscam a correção de uma situação de discriminação e desigualdade em que se encontram determinados grupos sociais. As ações afirmativas se baseiam no fundamento de que há uma dívida histórica com relação a grupos considerados minoritários e, por isso, as políticas públicas devem também ser voltadas para a reparação das desigualdades (idem, p1).

Holzer and Neumark (2000) colocam que as ações afirmativas podem ser diferenciadas de outras medidas anti-discriminatórias pelo requerimento de passos proativos (e por isso o termo "afirmativo") para eliminar diferenças entre grupos da sociedade, em contraste às leis especificas que evitam discriminação direta, como no caso da preferência de raça na contratação para um emprego.

Nessa mesma linha, Sander e Taylor (2012) colocam que o termo ação afirmativa se refere a esforços proativos para prevenir discriminação contra minorias e promover uma verdadeira igualdade de oportunidades por assegurar que os procedimentos de seleção são justos e pelo uso de divulgação e recrutamento para corrigir padrões passados de exclusão. Os autores chamam atenção para a diferença do termo preferência racial que, em contraste, descreve programas que alocam admissões universitárias ou outras oportunidades baseadas parcialmente na raça do candidato. 
No ensino superior público, as ações afirmativas se manifestam, em geral, no acesso à graduação por meio de reservas de vagas, sistema de cotas ou bonificação, e no sentido de permanência por meio de auxílio financeiro. No entanto, um conjunto adicional de ações pode ser considerado como elementos integrantes do programa. Em alguns casos, as instituições de ensino podem até mesmo realizar ações pré-ingresso e pós-permanência. As primeiras são voltadas para o ensino médio com o intuito de melhorar a qualidade dos prováveis candidatos à admissão nestas instituições. As segundas seriam ações voltadas para inserção dos egressos no mercado de trabalho.

As ações afirmativas para o acesso podem ser aplicadas por diferentes mecanismos. A mais discutida na literatura é a seleção dos grupos alvo, ou seja, aqueles que se encontram em desvantagem, por critério de raça. Este tipo de ação afirmativa é muito comum nos EUA, ainda que esteja se reduzindo consideravelmente ao longo dos últimos anos ${ }^{5}$ (KRISHNA e TARASOV, 2013). De forma resumida, a preferência racial na seleção dos grupos em desvantagem pode ser vista pelo estabelecimento de um determinado nível de presença dos grupos minoritários da sociedade, ou seja, cotas.

A seleção pode ainda ser realizada com base em um critério de bônus: os candidatos do grupo em desvantagem recebem um bônus (nota ou percentual adicional) sobre sua nota de ingresso na Universidade. Um terceiro critério de seleção seria o estabelecimento de um ponto de corte nos exames para ingresso nas Instituições de Ensino Superior diferenciado para o grupo em desvantagem. Estes dois últimos critérios podem também ser vistos como mecanismos que permitem algum tipo de concorrência ex-ante entre os potenciais beneficiários da política. Em geral, o que se observa é que as políticas adotadas não são exclusivamente baseadas em preferências raciais, mas fazem um mix do critério de preferência racial com sistema de concorrência entre os beneficiários da política.

No Brasil, as políticas de ações afirmativas surgem no contexto social de medidas redistributivas ou assistenciais aos grupos excluídos, tendo na década de 90 a primeira política de cota nacional por meio da lei que institui que os partidos políticos tivessem uma cota mínima de mulheres candidatas (MOEHLECKE, 2012). A primeira experiência com Ações Afirmativas nas universidades brasileiras públicas

\footnotetext{
Não apenas o critério de preferência racial tem se reduzido nos EUA como também o número de instituições que suspenderam as ações afirmativas de seus processos de seleção e admissão por identificarem forte efeito mismatch. Krishna e Tarasov (2013) colocam que "In 2003, the U.S. Supreme Court approved the use of "points" to promote a diverse student body. However, a number of states, such as Texas, have moved away from using only race based preferences and added other measures. Texas now gives the top $10 \%$ of students from public high schools in Texas automatic admission to the state's flagship public university, UT Austin, in addition to using points to belp diversify the student body as allowed by the 2003 supreme court ruling. The Supreme Court very recently ruled on Fisher versus the University of Texas which challenged the current policy.2 The ruling seems to have further reduced the space in which universities could give preferences" (p. 3).
} 
ocorreu no Rio de Janeiro através da adoção de cotas raciais para negros e indígenas na Universidade do Estado do Rio de Janeiro (UERJ) e na Universidade do Norte Fluminense (UENF) em 2001. Posteriormente outras universidades como a Universidade do Estado da Bahia (UNEB) e a Universidade Estadual do Mato Grosso do Sul (UEMS) também reservaram um percentual de vagas para afrodescendentes e indígenas (HERINGER; FERREIRA, 2009).

A Universidade Federal da Bahia (UFBA) adotou o sistema de reserva de vagas, também conhecido como sistema de cotas, para os ingressantes no vestibular de 2005, em julho de 2004, por meio da Resolução n01/04 elaborada pelo Conselho de Ensino, Pesquisa e Extensão (CONSEPE). A política de cotas estabeleceu que $45 \%$ (quarenta e cinco por cento) das vagas deveriam ser reservadas para estudantes oriundos de escolas públicas que se declarassem preto, pardo ou indígena. A política de cotas na UFBA foi fruto da conjuntura nacional e internacional que debatiam sobre a necessidade de reparação da exclusão sofrida pelos negros ao longo história (QUEIROZ; SANTOS, 2006).

A Lei ${ }^{\circ}$ 12.711/2012, sancionada em agosto de 2012, mudou o panorama do sistema de reserva de vagas brasileiro, tornando obrigatória a adoção do sistema por todas as Instituições Federais de Ensino Superior (IFES), englobando um total de 59 universidades federais e 38 institutos federais de educação ciência e tecnologia. A lei determina que $50 \%$ das matrículas das universidades e institutos federais sejam destinadas a alunos que frequentaram o ensino médio em colégios públicos e a outra metade a ampla concorrência. A "Lei de Cotas" funcionaria de acordo com o diagrama a seguir:

Figura 1: Diagrama da Lei no ${ }^{\circ} 12.711 / 2012$

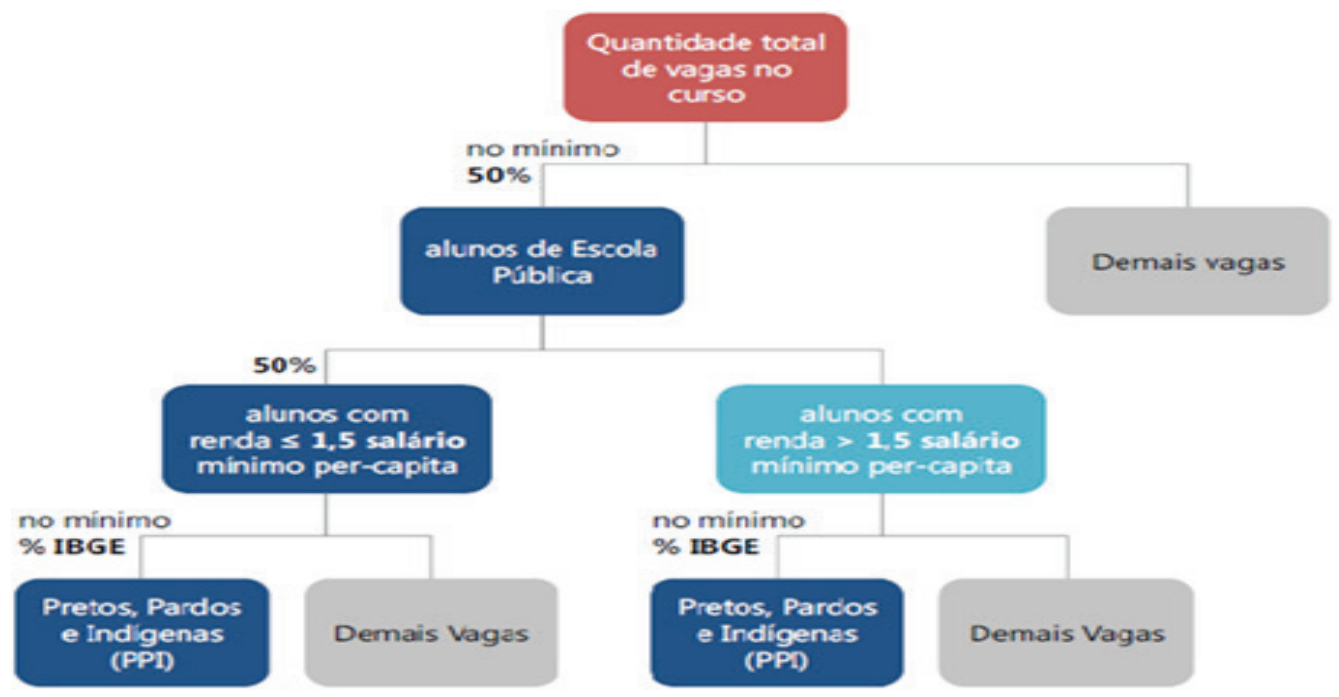

Fonte: Ministério da Educação (2013) 
No exemplo para o estado do Rio de Janeiro, em que 51,80\% da população se declararam preto, pardo ou indígena, um curso com a quantidade total de 100 vagas, conforme o esquema acima, 50 vagas para alunos de escola pública e 50 vagas de ampla concorrência. Dentro do primeiro grupo, 25 vagas para alunos com renda menor que um salário mínimo e meio e 25 vagas para alunos com renda maior que um salário mínimo e meio. E dentro de cada subgrupo seriam destinadas 13 vagas para negros, pardos e indígenas e 12 vagas para os demais (PORTAL MEC, 2013). A UFBA adotou a "Lei de Cotas" já para os ingressos no vestibular de 2013.

\subsection{Efeitos das ações afirmativas no ensino superior: evidências em- píricas}

Com relação à literatura empírica, Francis e Tannuri-Pianto (2012) identificam que a maioria dos trabalhos é sobre os EUA, embora muitos estudos sejam feitos sobre Índia e Brasil. Com relação à literatura americana deve-se chamar atenção para o crescente número de estudos que discutem os efeitos da eliminação das ações afirmativas, dados que aumenta o número de Estados que tem proibido ações afirmativas nos processos de admissão ${ }^{6}$. Os resultados encontrados por Garces (2012) identificam efeitos negativos do banimento das ações afirmativas em alguns estados americanos sobre a representação de estudantes de cor na educação pós secundaria. De acordo com a autora, a proibição nos estados do Texas, Califórnia, Washington, e Florida reduziu cerca de $12 \%$ a proporção média de estudantes de cor em todas as áreas de graduação incluídas na análise.

Bertrand et al. (2010), analisam as ações afirmativas no ensino superior indiano e propõem duas questões principais. A primeira é investigar as propriedades dos objetivos da política de ação afirmativa; a segunda saber se os candidatos minoritários que são favorecidos pela política de ação afirmativa nas admissões realmente se beneficiam economicamente com a participação na política, e se sim, como estes ganhos são comparados com as perdas potenciais da maioria dos candidatos deslocados pela política. Para responder às questões os autores coletaram dois bancos de dados, um para levantar informações sobre todos os candidatos a admissão no curso de engenharia em 1996 em um Estado da Índia, e outro banco a partir da entrevista com 700 famílias do censo de 1996, candidatos e pais, entre 2004 e 2006, para um melhor entendimento dos resultados entre grupos de castas.

Os resultados encontrados pelos autores mostram que a despeito dos baixos escores de entrada, os entrantes de baixa casta têm retorno de admissão positivo. Além disso, as estimativas encontradas sugerem que esses ganhos podem vir a um custo absoluto porque as perdas de rendimento experimentadas por candidatos de

\footnotetext{
De acordo com Garces (2012), os estados do Arizona, Califórnia, Washington, Michigan, e Nebraska implementaram a proibição por iniciativas aprovadas no voto ou em referendum. Florida e New Hampshire proibiram a pratica, respectivamente, por decisão executiva e voto legislativo.
} 
castas superiores deslocados são maiores do que os ganhos de renda deslocando estudantes de castas inferiores. Os autores chamam atenção para o fato de que o tamanho limitado da amostra nas especificações impede de tirar conclusões fortes destes resultados do mercado de trabalho.

Francis e Tannuri-Pianto (2012) analisam a experiência da UNB na implantação do sistema de reserva de vagas por critérios raciais em julho de 2004. A UNB reservava $20 \%$ das vagas para estudantes que se auto identificavam como negros. As informações utilizadas para estimação foram levantadas por entrevistas com estudantes admitidos na Universidade por meio de vestibular antes e depois da implantação das cotas, entre 2003 e 2005. Foram levantados diversos tipos de informações, como background familiar, expectativas, emprego, etc.

Os autores mostram que as cotas aumentaram a proporção de estudantes negros e que os beneficiários da política vinham de famílias de menor status socioeconômico do que os alunos não beneficiários. As evidências encontradas sugerem que as cotas raciais não reduzem o esforço pré-universidade dos estudantes e que pode existir razoável disparidade no desempenho acadêmico entre estudantes em departamentos selecionados. Os autores identificaram ainda que as cotas podem gerar um incentivo de deturpação da identidade racial ao mesmo tempo em que inspira indivíduos, especialmente o de pele mais escura, a declararem-se negros.

De acordo com Krishna e Tarasov (2013), os trabalhos que analisam os efeitos das ações afirmativas baseadas nas preferências raciais podem ser divididos em três linhas: modelos de discriminação estatística ${ }^{7}$, modelos de restrição de crédito e modelos de competição (contests). $\mathrm{Na}$ primeira linha, dominante na literatura, o argumento principal é de que considerando que a habilidade é não observada, mas correlacionada com alguma característica observável como raça, a preferência baseada na raça pode ser contraprodutiva ou mesmo criar desigualdade onde não existe. O chamado efeito de mismatch então prevalece gerando resultados não desejados pela política de ação afirmativa. Fang e Moro (2011) apresenta relação de artigos nesta linha.

A segunda linha analisa a política de ações afirmativas como forma de mitigar o acesso diferenciado à educação em decorrência das restrições de crédito. A terceira linha analisa a política em um ambiente de competição entre os estudantes. Em linhas gerais, os agentes competem para entrar na universidade de modo que este esforço aumenta o desempenho acadêmico com certo custo, embora o desempenho tenha um componente aleatório. A ação afirmativa, dando maior peso ao escore das minorias, poderia aumentar o esforço de todos os agentes, e se esse é o objetivo então a política pode ser desejável. Nesta linha podem ser citados os trabalhos de $\mathrm{Su}$ (2005), Fu (2007) e Krishna e Tarasov (2013).

De acordo com Fang e Moro (p. 134, 2011) discriminação estatística refere-se geralmente ao fenômeno do tomador de decisão usar características observáveis dos indivíduos, traços físicos facilmente reconhecíveis, como uma proxy para características relevantes não observáveis. Tais características observáveis são usadas para categorizar largamente grupos demográficos por raça, etnia ou gênero. 
O modelo de Su (2005) analisa o impacto da política de ações afirmativas no acesso à educação superior nos EUA, considerando dois aspectos diferenciadores dos demais modelos utilizados para avaliar o impacto desta política ${ }^{8}$. O primeiro aspecto considerado refere-se à introdução da competição entre os estudantes para ingressar na universidade, ou seja, na concorrência pelo acesso. A Ação Afirmativa pode introduzir mais competição entre os alunos, induzindo mais esforço e levando a resultados de capital humano melhores para todos os indivíduos, em ambos os grupos, beneficiários e não beneficiários da política.

A literatura nacional sobre o tema tem crescido consideravelmente. Santos (2012) realiza um levantamento e análise da produção intelectual existente sobre o tema e identifica que entre 2001 e 2011 a produção bibliográfica sobre a adoção de ações afirmativas no ensino superior cresceu significativamente. Sem considerar a publicação de livros, o autor identifica 232 trabalhos publicados, sendo 142 artigos, 71 dissertações e 19 teses. Santos argumenta que, além de crescente, a produção acadêmica sobre o tema também tem sido regular. No período considerado, a média de dissertações por ano foi 7,1; entre 2003 e 2010 a média por ano foi de 15 artigos, sendo 2009 foi o ano mais expressivo, com 24 artigos.

Analisando alunos da UFBA, Lordêlo (2004) coloca que o desempenho do estudante é uma função de multiplicidade que inclui fatores externos e internos ao ambiente escolar e que indica a qualidade do ensino prestado. Buscando construir o perfil do estudante do curso de Administração, o autor conclui que este é um curso elitizado, com baixa frequência de negros e pobres, o que mostra a necessidade de políticas promotoras da inclusão. Contudo, Lordêlo coloca que uma política de ação afirmativa não seria suficiente para garantir um bom desempenho durante o curso sendo necessária a combinação de algum tipo de auxílio financeiro, ou seja, a efetivação das ações de permanência.

Maia et al. (2009) propõe uma metodologia para analisar a heterogeneidade do desempenho dos alunos da UNICAMP, do ingresso à conclusão, considerando tipo de escola e gênero entre outros fatores. A partir da análise de diversidade, intra e entre grupos, os autores avaliam se existem diferenças de desempenho acadêmico entre alunos que fizeram ensino médio em escolas públicas e os que estudaram em escolas particulares. Utilizado dados de 1997 a 2000 de 45 cursos, de todas as áreas de conhecimento, os resultados encontrados mostraram que alunos oriundos de escolas públicas apresentaram uma melhor evolução relativamente aos de escolas privadas no primeiro ano dos cursos.

Queiroz e Santos (2006), analisando a política de reserva de vagas na UFBA, constataram que não existiam disparidades de desempenho acadêmico entre cotistas e não cotistas. Os autores concluíram que houve uma perceptível inclusão de

8 De acordo com Su (2005) a análise econômica do efeito da política de ações afirmativas sobre igualdade social e eficiência agregada já tem sido feita na literatura há algum tempo, o que inclui impactos sobre o mercado de trabalho e sobre a estrutura educacional. Ver em Su (2005) para detalhamento de referencias por tipos de análise. 
segmentos antes excluídos do ensino superior com a adoção da política e que alunos cotistas têm condições de ter rendimento satisfatório, o que inviabiliza o principal argumento contra as cotas.

Na mesma linha de Queiroz e Santos (2006), Velloso (2009) compara a nota média dos alunos ingressantes pelo sistema de reserva de vagas na UNB com a nota média dos demais ingressantes por vestibular nos anos de 2004 a 2006. O autor compara o rendimento de cotistas e não cotistas em cada carreira considerando o nível de prestigio social e área do conhecimento do vestibular (Humanidades, Ciências e Saúde). Os resultados encontrados por Velloso mostram que em cerca de dois terços das carreiras analisadas não há diferenças expressivas entre as médias dos dois grupos ou estas foram favoráveis aos cotistas. Esses resultados mostram, portanto, um efeito positivo da política de cotas (reserva de vagas) sobre o desempenho acadêmico dos alunos.

Waltenberg e Carvalho (2012) traçaram um perfil dos ingressantes nos cursos de graduação do Brasil com microdados do Enade 2008, concluindo que o desempenho de estudantes participantes de Ações Afirmativas é inferior aos demais alunos nas instituições de ensino superior pública. Eles interpretaram o resultado como o ônus que a sociedade paga ao promover a diversidade e oportunidades. Nas instituições de ensino superior privada, por outro lado, não apresenta um grande diferencial de desempenho entre os beneficiados e os não beneficiados por ações afirmativas, exceto em cursos de alto prestígio (cursos da área I- Ciências Físicas, Matemática e Tecnologia e II - Ciências Biológicas e Profissões da Saúde).

Silva Filho e Cunha (2013) fazem uma análise das políticas afirmativas sob a ótica dos direitos humanos e equidade. Os autores também analisam alguns antecedentes da implantação das políticas afirmativas no país e fazem um balanço dos estudos sobre os programas existentes nas universidades públicas. Os autores enfatizam os efeitos positivos da política sobre a promoção da igualdade ao mesmo tempo em que identificam na literatura a necessidade de uma discussão mais aprofundada da questão.

Analisando dados do Exame Nacional de Desempenho dos Estudantes (ENADE), Pereira (2013) estima o impacto das cotas sobre o desempenho acadêmico dos alunos no ano de 2008 em 59 cursos. Para tanto, o autor aplica o método de diferença-em-diferença (D-D) e o Propensity Matching Score (PMS). Os resultados mostram que a implantação das cotas impactou de forma negativa e significante nos cursos de Pedagogia, História e Física, e impactou positivamente e significante somente no curso de Agronomia.

$\mathrm{Na}$ literatura não existe um consenso acerca dos impactos das Ações Afirmativas dentro das universidades. Fryer e Loury (2005) afirmam que, teoricamente, é possível que a existência das ações afirmativas possa reduzir o esforço e aquisição de qualificação no grupo alvo porque a política poderia tornar esse esforço e aquisição menos importante para alcançar resultados de sucesso. Por outro lado, poderia aumentar os incentivos para o grupo-alvo, dado que as oportunidades criadas pelas 
ações afirmativas, antes fora do alcance deste grupo, tornam-se acessível de modo que o esforço para prosseguir torna-se totalmente válido.

$\mathrm{Su}(2005)$ defende as políticas de ações afirmativas colocando que estas promovem a igualdade racial. $\mathrm{O}$ grupo desfavorecido tem menos oportunidade de desenvolvimento, no que tange o acesso à educação baseado somente em pontuação, pois se trata de um grupo historicamente excluído, tornando necessária uma política de intervenção. A autora diz também que a ação afirmativa não significa perda de eficiência da universidade, visto que há um aumento da competitividade entre os estudantes pela vaga, acarretando o aumento do esforço e capital humano beneficiando a todos.

Uma parte da literatura identifica um efeito predominantemente negativo sobre os beneficiários das ações afirmativas. O debate sobre os efeitos da política foi fortemente influenciado pelo trabalho de Sander (2004) que discutiu e testou a hipótese de mismatch. De acordo com Sander, que este tipo de mecanismo ao invés de permitir a formação de capital humano para grupos historicamente em desvantagem, gera um efeito inverso em virtude do gap pré-existente à entrada na universidade. Assim é que, tem-se como resultado uma elevada taxa de reprovação e abandono dos beneficiários dessa política?.

Em geral, o efeito de mismatch ocorre porque os alunos não estão preparados de forma suficiente para acompanhar os cursos do qual participam, ou seja, acabam sendo inseridos em ambientes no qual se sentem sobrecarregados. Nesta perspectiva, os alunos que estão menos preparados, relativamente aos demais colegas, iniciam sua trajetória acadêmica com déficits, atrás dos demais, e ficam cada vez mais perdidos à medida que o curso avança. Sander e Taylor (2012) colocam ainda que o efeito de desanimo e consequente abandono da universidade pode ter forte impacto ao longo da vida destes indivíduos, o que seria ainda mais preocupante.

De acordo com Arcidiacono et al. (2011), a literatura sobre mismatch tem focado na comparação entre estudantes minoritários, matriculados em universidades de elite, relativo ao resultado contrafactual correspondente se estes estudantes minoritários estivessem matriculados em universidades menos seletivas. Um aspecto que está por detrás da hipótese de mismatch é que o processo educacional é inerentemente hierárquico, ou seja, a formação do conhecimento é feita de forma sequenciada, de modo que não é possível atingir estágios mais avançados sem ter passados pelos estágios básicos da formação. Como coloca Su (2005), a natureza hierárquica do processo educacional implica que etapas mais avançadas somente podem ser alcançadas se as etapas iniciais forem concluídas, e quanto melhor o desempenho no ensino básico, melhor a eficiência de aprendizagem no ensino superior. Então, se dificuldades de aprendizado são observados no ensino médio, certamente impactará no ensino superior.

Outra crítica à política é feita por Sowell (2004). De acordo com o autor, esse tipo de política, de caráter temporário, não diminui as desigualdades, dada uma

9 A apresentação da hipótese de mismatch levou a intensos debates na literatura, com réplicas e treplicas entre Sander e diversos autores. Barnes (2011) apresenta em nota de rodapé (3) a ordem cronológica deste debate na literatura. 
longa trajetória de desigualdade condicionada por uma enorme gama de fatores históricos, culturais, geográficos, demográficos, dentre outros, que molda habilidades específicas, hábitos e atitudes dos diferentes grupos da sociedade. Nesse sentido, existe um gap pré-existente na formação escolar entre beneficiários e não beneficiários que acarreta uma perda na qualidade do capital humano das universidades.

\subsection{Ações afirmativas na universidade federal da bahia}

Queiroz e Santos (2006) assinalam que a política de reserva de vagas na Universidade Federal da Bahia foi fruto da conjuntura nacional e internacional que debatiam sobre a necessidade de reparação da exclusão sofrida pelos negros ao longo história. Eles afirmam que a primeira proposta para o estabelecimento de cotas ocorreu em 2002 através do intermédio de um grupo de estudantes negros, porém a política só se tornou efetiva em 2005. A forma de ingresso na universidade mudou com a adoção de reservas de vagas, pois o sistema tradicional considerava exclusivamente o desempenho na primeira e segunda fase do vestibular, não importando variáveis como origem escolar, renda e cor na seleção (QUEIROZ; SANTOS, 2006).

De acordo com Almeida Filho et al. (2005), o Programa de Ação Afirmativa da UFBA foi destinado às populações socialmente carentes, afro-brasileiros e ameríndios e está estruturada em quatro eixos: preparação, ingresso, permanência, graduação. O primeiro eixo refere-se às ações adotadas que buscam influenciar positivamente a qualidade das escolas públicas na Bahia, melhorando dessa forma qualificação de seus egressos como candidatos ao vestibular. $\mathrm{O}$ segundo trata do ingresso na Universidade e é composto por três ações: redução da taxa e inscrição do vestibular e ampliação da isenção concedida a alunos socialmente carentes (egressos de escolas públicas), ampliação do número de vagas para cursos de graduação (vagas residuais, novos cursos e novas vagas em cursos pré-existentes), e sistema de cotas para alunos pobres, negros e índios descendentes. O terceiro é voltado para a permanência dos alunos incorpora três medidas: revisão da grade de horários de modo a permitir a combinação entre estudo e trabalho; implantação de um programa amplo de tutorial social, reforço escolar e acompanhamento acadêmico que atenda a todos os estudantes que demandarem, independente de terem ingressado pelo regime de cotas ou não; a ampliação da capacidade de atendimento dos programas de apoio estudantil, com mais bolsas de trabalho, bolsas residência e auxílio alimentação. E o quarto eixo trata do fomento a conclusão os cursos e preparação para o mercado de trabalho.

O sistema de cotas da UFBA, regulado pela Resolução 01/2004 do CONSE$\mathrm{PE}$, estabelecia que $45 \%$ (quarenta e cinco por cento) das vagas seriam reservadas. $\mathrm{O}$ critério para participar da reserva de vagas não era atrelado diretamente à cor declarada do candidato, o critério para ingresso através de reserva de vagas (cotista) era o tipo de escola - pública ou privada - que o candidato cursou durante todo o ensino médio e mais um ano do ensino fundamental, a cor declarada era um coadjuvante desse processo e não o fator determinante. No entanto, a UFBA organizava os candidatos em seis categorias de seleção organizadas da seguinte forma: 
Não sendo preenchidas as vagas destinadas a categoria $\mathrm{A}$ e $\mathrm{B}$, estas seriam disponibilizadas para a categoria C. Permanecendo ainda incompletas, seriam destinadas para candidatos da categoria E. O mesmo ocorre para a categoria $\mathrm{D}$, que não completando todas as vagas seriam disponibilizadas para a categoria E. Logo, as categorias não são mutuamente exclusivas, candidatos inscritos na categoria A não selecionados poderiam concorrer pela categoria $\mathrm{B}$ e se não selecionados nesta poderiam ainda concorrer pela categoria E. A categoria $\mathrm{F}$ ofereciam até duas vagas extras do total oferecido para candidatos declarados índios aldeados ou moradores das comunidades remanescentes dos quilombos, caso nas outras categorias tivessem candidatos da categoria $\mathrm{F}$ ou não houvesse número suficiente de candidatos aptos para preenchê-las não seria oferecida as vagas da categoria. O Diagrama 1 ilustra o sistema de reserva de vagas da UFBA.

Diagrama 1: Sistema de Cotas na UFBA por categorias - Resolução 01/2004

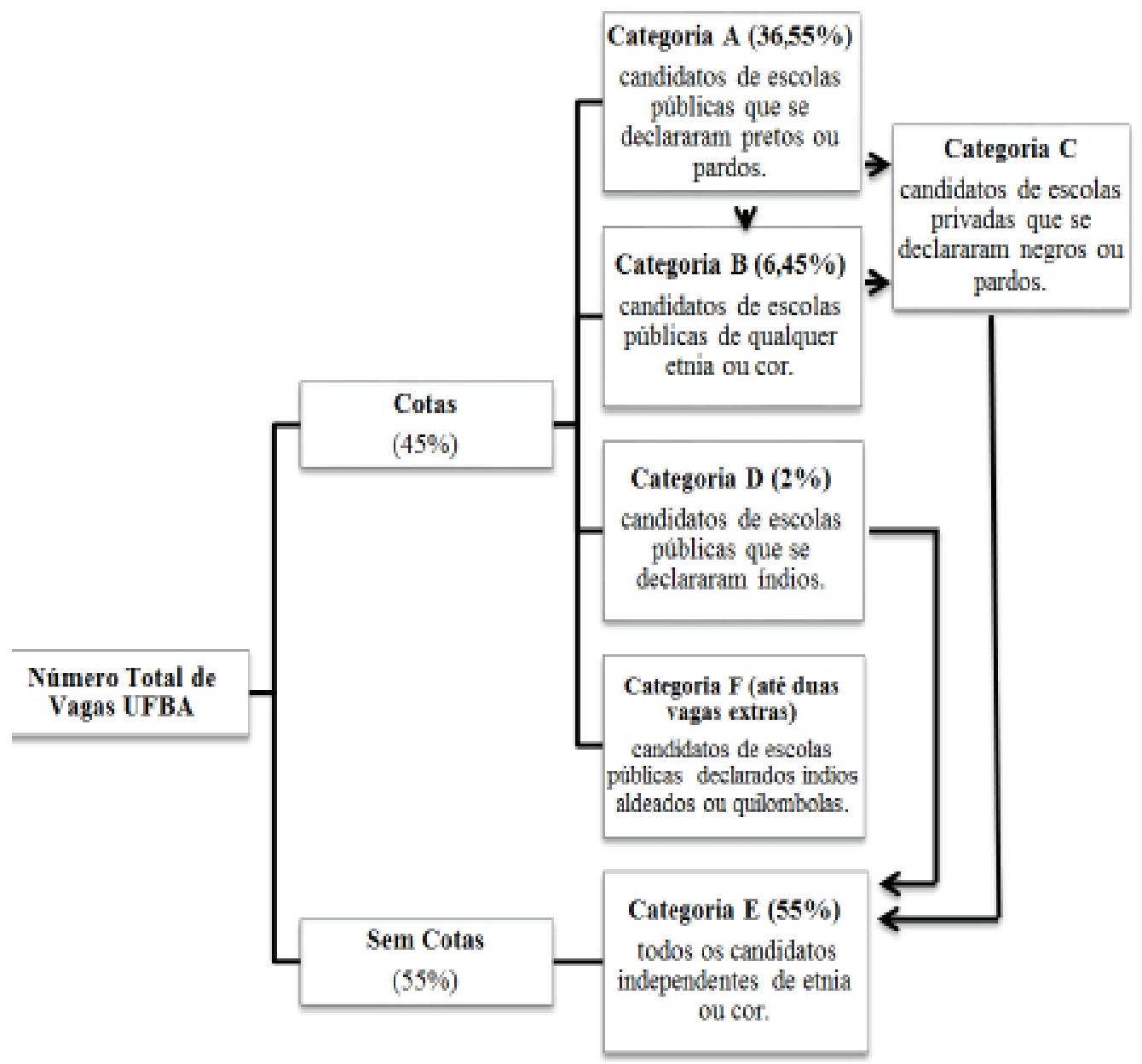

Fonte: Elaboração Própria 
Com a sanção da "Lei de Cotas", a UFBA reabriu as inscrições do vestibular para o ingresso em 2013, a fim de se adequar de imediato a nova resolução. Desse modo, tornou-se dispensável a exigência de ter estudado um ano do ensino fundamental em escola pública como vigorava anteriormente, tendo como critério único para se enquadrar no sistema os pré-requisitos exigidos por lei.

Este trabalho enquadra-se dentro desse contexto e é parte de um projeto de pesquisa que busca avaliar as ações afirmativas na Universidade Federal da Bahia. A análise aqui realizada considera incialmente um dos eixos do programa de ações afirmativas na UFBA: o acesso pelo sistema de reserva de vagas. Mais especificamente, busca-se identificar se existe diferencial de desempenho entre alunos ingressantes por meio das reservas de vagas e os demais alunos ingressantes por concorrência ampla.

Uma análise mais completa do programa requer, além de testar a existência de diferencial de desempenho, avaliar o desenvolvimento dos alunos cotistas, doravante assim chamados, ao longo do curso em que estão matriculados, em termos de frequência, aprovação e evasão. Esta análise complementar será feita em trabalho futuro. Considera-se neste trabalho todos os cursos da Universidade Federal da Bahia por grandes áreas de conhecimento do vestibular. Os dados, metodologia e resultados encontrados são apresentados na próxima sessão.

\section{Dados, Metodologia e Resultados}

Os dados utilizados referem-se aos estudantes matriculados nos cursos de graduação presencial da UFBA entre os anos de 2010 a 2012. Os dados foram disponibilizados pela Pró-Reitoria de Ensino de Graduação (PROGRAD) da Universidade Federal da Bahia e extraídos do Sistema Acadêmico (SIAC) da Universidade Federal da Bahia que é responsável pelo registro das notas. As informações relativas ao questionário socioeconômico que os candidatos preenchem na inscrição do vestibular foram disponibilizadas pelo Centro de Processamento de Dados da Universidade.

A amostra contém 13.367 observações (Tabela 1) para os três anos analisados e é composta apenas pelos estudantes aprovados no vestibular e que se matricularam na universidade. Os ingressantes através de transferência interna e externa, portadores de diploma de nível superior, aluno especial e os bacharelados interdisciplinares foram desconsiderados. Os estudantes não cotistas tiveram percentuais maiores em relação aos cotistas na amostra para o período considerado.

Tabela 1: Frequência de alunos da UFBA por categoria de seleção e ano

\begin{tabular}{c|c|c|c}
\hline Ano & Total de alunos & Não cotistas & Cotistas \\
\hline 2010 & 4.007 & $57,4 \%$ & $42,6 \%$ \\
\hline 2011 & 4.837 & $61,6 \%$ & $38,4 \%$ \\
\hline 2012 & 4.523 & $66,8 \%$ & $33,2 \%$ \\
\hline Total & 13.367 & $62,1 \%$ & $37,9 \%$ \\
\hline
\end{tabular}

Fonte: Elaboração própria com dados da UFBA (2013) 
A Tabela 2 mostra a porcentagem dos ingressantes por ano e categoria de seleção. Observa-se que os percentuais de alunos por categorias de seleção na amostra estão distribuídos de forma semelhante ao sugerido pela a Resolução 01/2004 do CONSEPE.

Tabela 2: Distribuição dos ingressantes por ano, categoria de seleção (\%)

\begin{tabular}{l|c|c|c}
\hline Categoria de Seleção & 2010 & 2011 & 2012 \\
\hline A - Cotas: preto ou pardo de escola pública & $36,1 \%$ & $35,5 \%$ & $36,3 \%$ \\
\hline B - Cotas: todas as etnias de escola pública & $5,8 \%$ & $6,0 \%$ & $6,0 \%$ \\
\hline C - Sem cotas: preto/pardo de escola privada & $2,4 \%$ & $3,3 \%$ & $3,1 \%$ \\
\hline D - Cotas: Índio-descendente de escola pública & $0,6 \%$ & $0,6 \%$ & $0,8 \%$ \\
\hline E - Sem cotas: todas as etnias de escola pública ou privada & $55,0 \%$ & $54,5 \%$ & $53,7 \%$ \\
\hline F - Cotas: Aldeado ou quilombola de escola pública & $0,1 \%$ & $0,1 \%$ & $0,1 \%$ \\
\hline
\end{tabular}

Fonte: Elaboração própria com dados da UFBA (2013)

Apesar da UFBA apresentar seis categorias de seleção, o critério principal para reserva de vagas é o tipo de escola (pública ou privada) cursada durante todo o ensino médio e mais um ano do ensino fundamental, logo o estudante é classificado como cotista e não cotista de acordo com este critério. A cor declarada do candidato não é o fator exclusivo ou primordial para participar ou não do sistema de cotas da universidade.

\subsection{Estatísticas descritivas}

Para verificar se existe diferencial de desempenho acadêmico entre alunos beneficiários do sistema de reserva de vagas e os demais na Universidade Federal da Bahia por grandes áreas de conhecimento, os estudantes foram considerados por meio de duas categorias de ingresso: cotistas - estudantes que ingressaram na universidade através de reserva de vagas - e não cotistas - os demais estudantes que ingressaram por ampla concorrência.

Com relação ao desempenho, duas estimativas foram consideradas: o escore final do vestibular e o coeficiente de rendimento (CR). O escore final é a pontuação obtida pelo estudante no vestibular. O coeficiente de rendimento é uma média das notas dos alunos, de todas as disciplinas cursadas. O CR se altera semestralmente conforme o número e créditos das disciplinas que o aluno se matricula e média de suas notas anteriores. Nesse cálculo se atribui zero àqueles que foram reprovados por falta. A Tabela 3 mostra as médias dos escores finais e do CR dos cotistas e não cotistas, por ano de ingresso.

Nota-se que, de forma geral, a média do escore final dos cotistas revela que o desempenho destes é mais homogêneo, ou seja, apresenta desvio padrão menor quando comparado à outra categoria. $\mathrm{Na}$ análise agregada, apesar da diferença não ser acentuada, os não cotistas apresentam melhor escore médio que os cotistas, o que é um 
resultado esperado, visto que o programa de ações afirmativas na UFBA tem como público alvo estudantes de escolas públicas e esses, quando comparado aos estudantes de escolas particulares, podem não ter acesso à mesma qualidade de educação.

Tabela 3: Escore final médio do vestibular e Coeficiente de Rendimento (CR) por ano de ingresso - 2010 a 2012

\begin{tabular}{c|c|c|c|c|c}
\hline $\begin{array}{c}\text { Ano de } \\
\text { Ingresso }\end{array}$ & Categoria & $\begin{array}{c}\text { Escore Final } \\
\text { médio }\end{array}$ & DP EF & CR médio & DP NM \\
\hline \multirow{3}{*}{2010} & Não cotista & $14.366,3$ & $2.077,4$ & 5,7 & 2,9 \\
\cline { 2 - 6 } & Cotista & $12.396,4$ & $1.558,4$ & 5,3 & 2,8 \\
\cline { 2 - 6 } & Total & $13.527,1$ & $2.111,9$ & 5,6 & 2,9 \\
\hline \multirow{3}{*}{2011} & Não cotista & $12.961,3$ & $3.348,5$ & 5,2 & 3,0 \\
\cline { 2 - 6 } & Cotista & $12.376,4$ & $1.538,9$ & 5,1 & 2,7 \\
\cline { 2 - 6 } & Total & $12.736,6$ & $2.809,8$ & 5,2 & 2,9 \\
\hline \multirow{3}{*}{2012} & Não cotista & $11.445,6$ & $4.237,6$ & 5,7 & 2,6 \\
\cline { 2 - 6 } & Cotista & $12.371,8$ & $1.556,6$ & 5,6 & 2,5 \\
\cline { 2 - 6 } & Total & $11.753,0$ & $3.604,3$ & 5,6 & 2,5 \\
\hline & Não cotista & $12.798,8$ & $3.621,0$ & 5,5 & 2,8 \\
\cline { 2 - 6 } & Cotista & $12.381,8$ & $1.550,5$ & 5,3 & 2,7 \\
\cline { 2 - 6 } & Total & $12.640,8$ & $3.015,6$ & 5,5 & 2,8 \\
\hline
\end{tabular}

Fonte: Elaboração própria com dados da UFBA (2013)

No entanto, para 2012 os cotistas tiveram escore médio final no vestibular maior que os não cotistas. Uma explicação razoável é a presença de outlier nos dados que, consequentemente, influência na média dos scores. Na mesma linha, outra possível explicação é a possível competição que ocorre entre os estudantes cotistas e acarreta em melhor preparação para o processo seletivo, visto que institutos federais e colégios militares são escolas públicas em que ensino tem qualidade diferenciada em relação às escolas públicas municipais e estaduais e, inclusive algumas escolas privadas, o que corrobora com o modelo de $\mathrm{Su}$ (2005) citado anteriormente neste artigo.

Com relação ao coeficiente de rendimento médio, observa-se que os não cotistas tiveram desempenho melhor que cotistas em todos os anos (Tabela 3). Em 2010, os não cotistas tiveram coeficiente de rendimento médio de 5,7 caindo no ano seguinte para 5,2 e 5,7 em 2012. Os cotistas, para o mesmo período, apresentaram CR médio de 5,3; 5,1 e 5,6, para cada um dos anos, respectivamente. Observa-se que os cotistas conseguiram manter um desempenho próximo a média para o conjunto de anos $(5,3)$, diferentemente dos não cotistas. Entretanto, os desvios padrão de ambas as categorias revelam que as notas não foram muito heterogêneas. 
A política de ação afirmativa não seria necessária se fossem esperados que os cotistas e não cotistas tivessem o mesmo desempenho (VELLOSO, 2009). Assim, observa-se que de fato existe diferencial de desempenho entre os dois grupos, porém estas diferenças não são extremas e nem estariam gerando um efeito inverso como sugerido por Sander (2004) ou influenciando negativamente na formação do capital da universidade como sugerido por Sowell (2004).

Considerando escore final médio por gênero e categoria de ingresso, conforme apresentado na Tabela 4, observa-se que o gênero feminino é maioria em todos os anos analisados. No entanto, o gênero masculino apresenta melhor escore final do vestibular que o feminino independente da categoria de seleção observada. Conforme apontado anteriormente, no ano de 2012 ambos os gêneros cotistas apresentaram resultados melhores em comparação a ambos os gêneros não cotistas.

Tabela 4: Escore final médio do vestibular e coeficiente de rendimento por categoria, gênero e ano

\begin{tabular}{|c|c|c|c|c|c|c|c|}
\hline $\begin{array}{l}\text { Ano de } \\
\text { Ingresso }\end{array}$ & Gênero & Cotas & $\begin{array}{c}\mathrm{N}^{\mathrm{o}} \\
\text { alunos }\end{array}$ & $\begin{array}{l}\text { Escore Final } \\
\text { médio }\end{array}$ & DP EF & $\begin{array}{c}\mathrm{CR} \\
\text { médio }\end{array}$ & $\begin{array}{l}\text { DP } \\
\mathrm{NM}\end{array}$ \\
\hline \multirow{4}{*}{2010} & \multirow{2}{*}{$\begin{array}{c}\text { Feminino } \\
(53,7 \%)\end{array}$} & $\begin{array}{c}\text { Não cotistas } \\
(57,4 \%)\end{array}$ & 1235 & 14065,9 & 2034,1 & 6,9 & 1,6 \\
\hline & & $\begin{array}{l}\text { Cotistas } \\
(42,6 \%) \\
\end{array}$ & 916 & 12129,8 & 1385,5 & 6,4 & 1,7 \\
\hline & \multirow{2}{*}{$\begin{array}{c}\text { Masculino } \\
(46,3 \%)\end{array}$} & $\begin{array}{c}\text { Não cotistas } \\
(57,4 \%)\end{array}$ & 1065 & 14714,7 & 2073,7 & 6,2 & 2,0 \\
\hline & & $\begin{array}{l}\text { Cotistas } \\
(42,6 \%)\end{array}$ & 791 & 12705,2 & 1686,1 & 5,5 & 2,0 \\
\hline \multirow{4}{*}{2011} & \multirow{2}{*}{$\begin{array}{c}\text { Feminino } \\
(53,5 \%)\end{array}$} & $\begin{array}{c}\text { Não cotistas } \\
(61,6 \%)\end{array}$ & 1594 & 12784,6 & 3223,5 & 6,3 & 2,1 \\
\hline & & $\begin{array}{l}\text { Cotistas } \\
(38,4 \%)\end{array}$ & 995 & 12149,3 & 1433,8 & 6,1 & 1,9 \\
\hline & \multirow{2}{*}{$\begin{array}{c}\text { Masculino } \\
(46,5 \%)\end{array}$} & $\begin{array}{c}\text { Não cotistas } \\
(61,6 \%)\end{array}$ & 1385 & 13164,7 & 3476,9 & 5,4 & 2,4 \\
\hline & & $\begin{array}{l}\text { Cotistas } \\
(38,4 \%)\end{array}$ & 863 & 12638,1 & 1613,6 & 5,2 & 2,2 \\
\hline \multirow{4}{*}{2012} & \multirow{2}{*}{$\begin{array}{c}\text { Feminino } \\
(54,7 \%)\end{array}$} & $\begin{array}{c}\text { Não cotistas } \\
(67,6 \%)\end{array}$ & 1673 & 11179,6 & 4226,2 & 6,2 & 2,1 \\
\hline & & $\begin{array}{l}\text { Cotistas } \\
(32,4 \%) \\
\end{array}$ & 801 & 12110,4 & 1400,9 & 6,1 & 1,9 \\
\hline & \multirow{2}{*}{$\begin{array}{c}\text { Masculino } \\
(45,3 \%)\end{array}$} & $\begin{array}{c}\text { Não cotistas } \\
(65,8 \%)\end{array}$ & 1349 & 11775,5 & 4230,1 & 5,5 & 2,4 \\
\hline & & $\begin{array}{l}\text { Cotistas } \\
(34,2 \%)\end{array}$ & 700 & 12670,9 & 1669,1 & 5,5 & 2,3 \\
\hline
\end{tabular}

Fonte: Elaboração própria com dados da UFBA (2013) 
Com relação ao coeficiente de rendimento, o gênero feminino apresenta melhores notas que o gênero masculino, o que implica que o melhor desempenho do gênero masculino no ingresso (escore final do vestibular) não se mantém ao longo do curso. Observa-se ainda, que as mulheres cotistas conseguem ter melhor aproveitamento tanto em relação aos homens cotistas quanto em relação aos homens não cotistas para os três anos analisados.

A tabela 5 apresenta o escore médio do vestibular e o coeficiente de rendimento médio por área de conhecimento e ano de ingresso. Nota-se que a área I é a que apresenta a maior diferença de coeficiente de rendimento entre cotistas e não cotistas, sendo esta diferença também vista no escore final médio. Isto pode estar atrelado às características dos cursos que englobam está área, em que é necessário um bom domínio de disciplinas quantitativas como matemática e física para conseguir acompanhar o curso. Disciplinas em que o aprendizado é hierarquizado (não se aprende a multiplicar e dividir sem antes aprender a somar e subtrair) evidenciam as fragilidades daqueles que não tiveram um ensino básico de qualidade. A mesma análise é sugerida para a área II (Ciências Biológicas e Profissões da Saúde). Um fator importante é que as duas áreas são compostas dos cursos de maior tradição e consequentemente, maior concorrência, sendo esperado notas mais elevadas.

Tabela 5: Escore final médio do vestibular e coeficiente de rendimento por ano e área

\begin{tabular}{|c|c|c|c|c|c|c|c|}
\hline Área & Ano & Categoria & $\begin{array}{c}\mathrm{N}^{\mathrm{O}} \\
\text { alunos }\end{array}$ & $\begin{array}{c}\text { Escore Final } \\
\text { médio }\end{array}$ & $\mathrm{DP}$ & $\begin{array}{l}\text { CR } \\
\text { médio }\end{array}$ & $\mathrm{DP}$ \\
\hline \multirow{6}{*}{$\begin{array}{l}\text { I- Matemática, } \\
\text { Ciências Físicas } \\
\text { e Tecnologia }\end{array}$} & \multirow{2}{*}{2010} & Não cotistas & 654 & 14627,7 & 1888,6 & 6,0 & 1,9 \\
\hline & & Cotistas & 417 & 12174,4 & 1394,2 & 4,9 & 1,9 \\
\hline & \multirow{2}{*}{2011} & Não cotistas & 856 & 13310,3 & 3388,3 & 5,3 & 2,3 \\
\hline & & Cotistas & 493 & 12158,9 & 1225,3 & 4,7 & 1,9 \\
\hline & \multirow{2}{*}{2012} & Não cotistas & 909 & 11701,5 & 4229,2 & 5,6 & 2,2 \\
\hline & & Cotistas & 385 & 12283,8 & 1324,5 & 5,2 & 2,0 \\
\hline \multirow{6}{*}{$\begin{array}{l}\text { II- Ciências } \\
\text { Biológicas e } \\
\text { Profissões } \\
\text { da Saúde }\end{array}$} & \multirow{2}{*}{2010} & Não cotistas & 593 & 14357,7 & 2184,6 & 6,8 & 1,5 \\
\hline & & Cotistas & 476 & 12328,9 & 1664,0 & 6,2 & 1,6 \\
\hline & \multirow{2}{*}{2011} & Não cotistas & 756 & 12600,0 & 3515,9 & 6,3 & 1,8 \\
\hline & & Cotistas & 463 & 12337,2 & 1639,6 & 6,0 & 1,7 \\
\hline & \multirow{2}{*}{2012} & Não cotistas & 805 & 10627,3 & 4472,6 & 5,9 & 2,0 \\
\hline & & Cotistas & 420 & 12377,1 & 1698,7 & 5,9 & 1,7 \\
\hline
\end{tabular}


(continua)

\begin{tabular}{|c|c|c|c|c|c|c|c|}
\hline \multirow{6}{*}{$\begin{array}{c}\text { III- Filosofia } \\
\text { e Ciências } \\
\text { Humanas }\end{array}$} & \multirow{2}{*}{2010} & Não cotistas & 761 & 14048,6 & 2046,4 & 6,9 & 1,8 \\
\hline & & Cotistas & 623 & 12369,3 & 1282,7 & 6,4 & 1,9 \\
\hline & \multirow{2}{*}{2011} & Não cotistas & 997 & 12706,4 & 3259,8 & 6,1 & 2,4 \\
\hline & & Cotistas & 677 & 12280,8 & 1285,1 & 6,0 & 2,1 \\
\hline & \multirow{2}{*}{2012} & Não cotistas & 1009 & 11187,5 & 4061,1 & 6,2 & 2,4 \\
\hline & & Cotistas & 539 & 12265,7 & 1368,9 & 6,1 & 2,3 \\
\hline \multirow{6}{*}{ IV- Letras } & \multirow{2}{*}{2010} & Não cotistas & 142 & 12812,2 & 1156,3 & 6,3 & 2,1 \\
\hline & & Cotistas & 106 & 11595,0 & 861,8 & 6,1 & 1,7 \\
\hline & \multirow{2}{*}{2011} & Não cotistas & 198 & 11994,1 & 2217,0 & 5,3 & 2,6 \\
\hline & & Cotistas & 123 & 11541,7 & 980,5 & 5,5 & 2,2 \\
\hline & \multirow{2}{*}{2012} & Não cotistas & 150 & 11960,0 & 2024,9 & 5,6 & 2,7 \\
\hline & & Cotistas & 96 & 11535,5 & 1096,2 & 5,5 & 2,2 \\
\hline \multirow{6}{*}{ V-Artes } & \multirow{2}{*}{2010} & Não cotistas & 150 & 16343,8 & 1521,8 & 6,6 & 1,9 \\
\hline & & Cotistas & 85 & 15061,7 & 1627,9 & 6,7 & 1,7 \\
\hline & \multirow{2}{*}{2011} & Não cotistas & 172 & 15403,9 & 2660,7 & 6,2 & 2,5 \\
\hline & & Cotistas & 102 & 15245,8 & 1502,4 & 6,9 & 2,2 \\
\hline & \multirow{2}{*}{2012} & Não cotistas & 149 & 15535,2 & 3175,5 & 6,8 & 2,5 \\
\hline & & Cotistas & 61 & 15144,4 & 1185,9 & 7,3 & 2,2 \\
\hline
\end{tabular}

Fonte: Elaboração própria com dados da UFBA (2013)

$\mathrm{Na}$ área III (Filosofia e Ciências Humanas), observam-se diferenças menores, apesar de contar com cursos tradicionais como Direito e Administração. Os cursos desta área são, em geral, de caráter menos quantitativo e mais interpretativo, ou seja, o background escolar pode não ser tão decisivo, quando comparado às áreas I e II, do ponto de vista da do caráter cumulativo das disciplinas ao longo do curso.

Para as áreas IV (Letras) e V (Artes), apesar dos estudantes não cotistas apresentarem melhor escore final médio que os cotistas, a ordem dos CR médios é inversa: cotistas apresentam melhor desempenho. Uma possível explicação para este resultado deve-se ao fato de são áreas em que as disciplinas de caráter cumulativo não fazem parte da grade dos cursos, pelo menos de forma tão ampla como nos cursos das áreas I e II. Ademais, na área V particularmente, a habilidade individual é um dos fatores de bastante influência para o desempenho pré e pós-ingresso do estudante. Outro aspecto relevante a ser considerado é que nestas áreas a maior parte dos cursos é de baixa concorrência. 
A Tabela 6 apresenta algumas das variáveis presentes no banco de dados relativas ao perfil social e econômico da amostra ${ }^{10}$.

Tabela 6: Frequência de variáveis selecionadas por ano e categoria de seleção

\begin{tabular}{|c|c|c|c|c|c|c|}
\hline $\begin{array}{l}\text { Ano de } \\
\text { Ingresso }\end{array}$ & $\begin{array}{l}\text { Total de } \\
\text { Alunos }\end{array}$ & Categoria & $\begin{array}{c}\text { Escola } \\
\text { Pública } \\
(\%)\end{array}$ & $\begin{array}{l}\text { Idade } \\
\text { (média) }\end{array}$ & $\begin{array}{c}\text { Computador } \\
\text { pessoal ou } \\
\text { familiar }(\%)\end{array}$ & $\begin{array}{c}\text { Automóvel } \\
\text { para uso } \\
\text { pessoal }(\%)\end{array}$ \\
\hline \multirow{2}{*}{2010} & \multirow{2}{*}{4007} & Não cotistas & 57,3 & 20,9 & 91,8 & 25,5 \\
\hline & & Cotistas & 100,0 & 22,5 & 80,5 & 16,2 \\
\hline \multirow{2}{*}{2011} & \multirow{2}{*}{4837} & Não cotistas & 27,8 & 21,3 & 93,4 & 19,0 \\
\hline & & Cotistas & 99,9 & 22,7 & 75,8 & 10,2 \\
\hline \multirow{2}{*}{2012} & \multirow{2}{*}{4523} & Não cotistas & 32,4 & 20,4 & 93,0 & 21,4 \\
\hline & & Cotistas & 99,9 & 22,5 & 81,0 & 11,4 \\
\hline
\end{tabular}

Fonte: Elaboração própria com dados da UFBA (2013)

É importante ressaltar que uma das exigências para o estudante participar da política de cotas da UFBA era ter estudado todo o ensino médio em pelo menos um ano do ensino fundamental em escola pública, portanto estudantes que estudaram em escola privada até o ensino fundamental e migraram para escola pública apenas no ensino médio não são beneficiados pelo sistema de reserva de vagas. Contudo, em 2011 e em 2012, a amostra identificou um aluno oriundo de escola particular e que ingressou na universidade pelo sistema de reserva de vagas (representando pelo percentual de $99,9 \%$ ) validando a natureza não excludente das categorias de seleção apresentadas na seção anterior. Dos ingressantes em 2010, observa-se que o maior percentual de não cotistas foram oriundos de escolas públicas $(57,3 \%)$, no ano seguinte este percentual reduziu a quase metade $(27,3 \%)$ e volta a aumentar em $2012(30,2 \%)$.

Os cotistas, de modo geral, apresentam maior idade média que os não cotistas. Considerando que o ingresso na universidade, para aqueles que fizeram o ensino regular, deveria ser aos 18 anos, ambos os grupos estão acima da média, porém não é uma variação preocupante e que represente alguma possível causa para o diferencial de desempenho. Em relação às variáveis selecionadas para análise das condições econômicas (computador pessoal e automóvel próprio) tem-se que, em geral, os não cotistas apresentam indicadores superiores. Contudo, observa-se que

10 Em 2010 cerca de 50\% dos questionários socioeconômicos tiveram parte das questões sem respostas, possivelmente decorrente de algum problema técnico, visto que para 2011, em ambas as categorias de seleção, menos de 7\% não continham informações e para 2012 esse percentual ficou em torno de $5 \%$. A despeito disso, dado o número de estudantes ingressantes em 2010, a ausência de informações permite trabalhar com uma amostra restante de tamanho suficientemente grande. 
as diferenças, pelo menos com relação às variáveis escolhidas, não são extremas como poderia ser esperado ${ }^{11}$.

Estudos em Economia da Educação tem apresentado evidencias de que a escolaridade dos genitores ou responsáveis pelo estudante, mais fortemente das mães, é um fator de impacto no desempenho destes indivíduos em sua vida escolar. Nesse sentido, a Tabela 7 apresenta a distribuição dos estudantes por nível de escolaridade da mãe, categoria e ano de ingresso. É possível observar que cerca de $50 \%$ das mães dos alunos não cotistas frequentaram pelo menos até o nível superior, diferentemente dos cotistas, em que este percentual não ultrapassou $17 \%$. O perfil escolar das mães dos estudantes cotistas é majoritariamente com até o segundo grau completo (entre 45 e $49 \%$ ), sendo que o nível de escolaridade com até o primário completo é a segunda categoria de maior participação entre cotistas, muito superior aos percentuais dos estudantes não cotistas.

Tabela 7: Distribuição percentual dos estudantes categoria de ingresso e nível de escolaridade da mãe - 2010, 2011 e 2012

\begin{tabular}{c|c|c|c|c|c|c}
\cline { 2 - 7 } & \multicolumn{2}{c|}{2010} & \multicolumn{2}{c|}{2011} & \multicolumn{2}{c}{2012} \\
\hline Escolaridade da Mãe & $\begin{array}{c}\text { Não } \\
\text { Cotistas }\end{array}$ & Cotistas & $\begin{array}{c}\text { Não } \\
\text { Cotistas }\end{array}$ & Cotistas & $\begin{array}{c}\text { Não } \\
\text { Cotistas }\end{array}$ & Cotistas \\
\hline Nunca frequentou & 0,3 & 2,4 & 0,5 & 2,0 & 0,6 & 2,7 \\
\hline Até o Primário Completo & 3,0 & 18,3 & 5,1 & 20,8 & 5,3 & 18,4 \\
\hline Até o Ginásio Completo & 4,9 & 14,0 & 5,6 & 14,4 & 7,3 & 16,1 \\
\hline Até o Colegial Completo & 36,0 & 49,0 & 36,8 & 47,3 & 39,0 & 45,2 \\
\hline Até o Superior Completo & 55,1 & 15,4 & 51,1 & 14,3 & 47,2 & 16,8 \\
\hline Não souberam informar & 0,7 & 0,9 & 0,9 & 1,3 & 0,6 & 0,9 \\
\hline
\end{tabular}

Fonte: Elaboração própria com dados da UFBA (2013)

A Tabela 8 indica a distribuição dos discentes por faixa de renda, categoria de seleção e ano de ingresso. A renda total da família é obtida considerando a soma de todos os rendimentos individuais daqueles que moram com o estudante. Em 2010, cerca de $50 \%$ dos estudantes não apresentaram resposta para renda familiar total, para ambas as categorias, enquanto que em 2011 e 2012 esse percentual ficou em torno de $7 \%$. Em termos agregados, os estudantes têm maior concentração nas faixas de renda entre 1 e 10 salários mínimos, cerca de 60\% (coluna 4).

Em 2010, os estudantes não cotistas encontravam-se majoritariamente entre as faixas de renda maior do que 3 salários mínimos e menor do que 20 salários mí-

11 Certamente a ampliação do crédito pessoal possibilitou o acesso à tecnologia e bens de consumo duráveis e semiduráveis para uma larga parcela da população, de média e baixa renda. 
nimos, de $35 \%$. Já os cotistas apresentaram maior concentração nas faixas de renda entre 1 e 5 salários mínimos, 36,5\%. Em 2011, nota-se um maior percentual de não cotistas na faixa de renda de 1 a 3 salários mínimos (21,3\%), com concentração nas faixas de renda entre 1 e 10 salários mínimos (65\%), sendo que em o percentual de não cotistas com renda familiar entre 10 e 20 salários mínimos foi relativamente elevado, $17 \%$. Neste ano, os cotistas estavam mais concentrados na faixa de renda entre 1 e 3 salários mínimos, 49,1\%.

No ano de 2012, a distribuição para ambas as categorias segue o padrão da observada em 2011: concentração de não cotistas nas faixas maior que 1 e menor até 10 salários mínimos, porém com maior participação na faixa de 1 a 3 salários mínimos (26,6\%) e menor participação na faixa de 10 a 20 salários mínimos (13,4\%). Para os cotistas observou-se uma maior participação na faixa de renda mais baixa, 18,5\%, com concentração dos estudantes nas faixas de renda de 1 até 5 salários mínimos.

Vale notar que para ambas as categorias se observou aumento do percentual de estudantes na faixa de renda até 1 salário mínimo, para não cotistas esse percentual mais do que dobrou enquanto para cotistas esse percentual cresceu menos de 2 pontos percentuais.

Tabela 8: Distribuição percentual dos estudantes por categoria de ingresso e faixa de renda - 2010, 2011 e 2012

\begin{tabular}{c|c|c|c|c|c|c|c}
\cline { 2 - 8 } & \multicolumn{2}{c|}{2010} & \multicolumn{2}{c|}{2011} & \multicolumn{2}{c}{2012} & $\begin{array}{c}2010 \\
\text { a } 2012\end{array}$ \\
\hline $\begin{array}{c}\text { Faixa de Renda } \\
\text { Familiar }\end{array}$ & $\begin{array}{c}\text { Não } \\
\text { Cotistas }\end{array}$ & Cotistas & $\begin{array}{c}\text { Não } \\
\text { Cotistas }\end{array}$ & Cotistas & $\begin{array}{c}\text { Não } \\
\text { Cotistas }\end{array}$ & Cotistas & Média \\
\hline Até 1 SM & 0,7 & 7,5 & 2,9 & 16,9 & 6,1 & 18,5 & 7,5 \\
\hline $\begin{array}{c}\text { Maior que } \\
\text { 1 até 3 SM }\end{array}$ & 8,7 & 25,5 & 21,3 & 49,1 & 26,6 & 48,8 & 27,8 \\
\hline $\begin{array}{c}\text { Maior que } \\
3 \text { até 5 SM }\end{array}$ & 11,3 & 11,0 & 22,1 & 16,7 & 21,0 & 16,5 & 17,2 \\
\hline $\begin{array}{c}\text { Maior que } \\
\text { até 10 SM }\end{array}$ & 13,0 & 4,9 & 21,5 & 8,1 & 20,4 & 7,7 & 14,2 \\
\hline $\begin{array}{c}\text { Maior que } \\
10 \text { até 20 SM }\end{array}$ & 10,4 & 1,3 & 17,0 & 2,4 & 13,4 & 2,7 & 9,4 \\
\hline $\begin{array}{c}\text { Maior que } \\
20 \text { até 40 SM }\end{array}$ & 5,3 & 0,2 & 6,0 & 0,5 & 5,8 & 0,6 & 3,7 \\
\hline $\begin{array}{c}\text { Maior que } \\
40 \text { SM }\end{array}$ & 0,7 & 0,1 & 2,3 & 0,0 & 2,5 & 0,1 & 1,2 \\
\hline \begin{tabular}{c} 
Sem Resposta \\
\hline
\end{tabular} & 49,9 & 49,6 & 6,9 & 6,2 & 4,2 & 5,2 & 18,9 \\
\hline
\end{tabular}

Fonte: Elaboração própria com dados da UFBA (2013) 
Esses resultados podem estar indicando a eficácia da política de cotas na UFBA, uma vez que tem possibilitado o acesso de estudantes oriundos de condições econômicas menos privilegiadas, os quais, possivelmente, na ausência de cotas, teriam menos condições de competir com estudantes vindo de famílias com nível de renda mais elevado. A renda familiar é importante condicionante na análise do desempenho dos discentes, pois influencia na qualidade do ciclo básico educacional que estes estudantes tiveram acesso, assim como a estrutura para desenvolver todas as atividades e capacidades intelectuais.

Para os estudantes de baixa renda, o caminho de acesso à Universidade apresenta inúmeros obstáculos, muitas vezes decorrentes da condição econômica. Ingressar no ensino superior público é apenas uma das etapas a serem vencidas. Estudantes com renda familiar mais baixa podem ter dificuldades em se manter integralmente nos estudos, seja pela necessidade de complementar a renda familiar, por meio de sua participação no mercado de trabalho, mesmo antes do ingresso na universidade, seja por não terem acesso conjunto de materiais didáticos necessários, por exemplo. Exatamente por isso é que a Política de Ações Afirmativas no ensino superior requer a existência de outros eixos de ação, quais sejam, o de permanência e assistência estudantil.

Nesse sentido é que desde 2006 a UFBA conta com a Pró-Reitoria de Ações Afirmativas e Assistência Estudantil (PROAE) que busca garantir a permanência e auxiliar a trajetória desses estudantes beneficiados pelas ações afirmativas, com serviços de creche, restaurante universitário e residência universitária. Além disso, outros programas e ações têm sido desenvolvidos para atender à permanência destes estudantes, os quais englobam ajustamento de grade curricular, reforço e acompanhamento escolar e apoio estudantil (bolsas de trabalho, e auxílios residência e alimentação). Tais mecanismos e instrumentos de ação são fundamentais para permitir que os estudantes vivenciem plenamente a universidade, acadêmica e socialmente.

Como já ressaltado anteriormente, o sistema de reserva de vagas da UFBA tem caráter prioritariamente social uma vez que o critério fundamental para ser um potencial beneficiário do sistema é ter feito ensino médio em escola pública. No entanto, a questão racial não deixa de ser importante mesmo porque compõe um dos critérios de classificação do cotista. Nesse sentido, a Tabela 9 apresenta a distribuição dos estudantes por faixas de renda familiar, categoria de ingresso e etnia para todo o período de análise, de forma agregada ${ }^{12}$. Nesta tabela foram consideradas apenas as observações com respostas válidas, ou seja, somente aqueles que responderam às questões de renda e etnia.

A tabela 9 pode ser lida da seguinte forma: as linhas (1) apresentam o percentual de estudantes não cotistas por etnia na faixa de renda; as linhas (2) o percentual dos cotistas na faixa de renda por etnia; as linhas (3) o percentual dos estudantes na faixa de renda por etnia; as linhas (4) apresentam o percentual de estudantes da

12 A análise separada por ano apresentou perfil muito próximo à análise agregada de todo o período. 
etnia por faixa de renda. No final da tabela, a linha Total apresenta a distribuição dos estudantes por etnia: total e por categoria de ingresso.

Tabela 9: Distribuição percentual dos estudantes por categoria de ingresso, faixa de renda e etnia - 2010 a 2012

\begin{tabular}{|c|c|c|c|c|c|c|c|}
\hline $\begin{array}{c}\text { Faixa de } \\
\text { renda }\end{array}$ & Categoria & Aldeado & Índio & Outro & Pardo & Preto & Quilombola \\
\hline \multirow{3}{*}{$\begin{array}{l}\text { Até } \\
1 \mathrm{SM}\end{array}$} & Não cotistas & 0,0 & 1,7 & 10,1 & 46,9 & 41,3 & 0,0 \\
\hline & Cotistas & 0,1 & 4,3 & 6,4 & 44,3 & 44,3 & 0,6 \\
\hline & \% por etnia & 0,1 & 3,6 & 7,5 & 45,0 & 43,4 & 0,4 \\
\hline \multirow{3}{*}{$\begin{array}{l}\text { Maior que } \\
1 \text { até } 3 \mathrm{SM}\end{array}$} & Não cotistas & 0,2 & 0,7 & 16,2 & 53,6 & 29,4 & 0,0 \\
\hline & Cotistas & 0,0 & 2,0 & 6,9 & 52,5 & 38,4 & 0,2 \\
\hline & $\%$ por etnia & 0,1 & 1,4 & 11,0 & 53,0 & 34,4 & 0,1 \\
\hline \multirow{3}{*}{$\begin{array}{l}\text { Maior que } \\
3 \text { até } 5 \mathrm{SM}\end{array}$} & Não cotistas & 0,3 & 0,6 & 26,3 & 54,4 & 18,3 & 0,1 \\
\hline & Cotistas & 0,0 & 1,7 & 8,2 & 59,1 & 31,0 & 0,0 \\
\hline & \% por etnia & 0,2 & 1,0 & 20,4 & 55,9 & 22,4 & 0,0 \\
\hline \multirow{3}{*}{$\begin{array}{l}\text { Maior que } \\
5 \text { até } 10 \mathrm{SM}\end{array}$} & Não cotistas & 0,3 & 0,5 & 36,7 & 50,4 & 12,2 & 0,0 \\
\hline & Cotistas & 0,0 & 0,6 & 12,0 & 66,8 & 20,6 & 0,0 \\
\hline & $\%$ por etnia & 0,2 & 0,5 & 32,2 & 53,4 & 13,8 & 0,0 \\
\hline \multirow{3}{*}{$\begin{array}{c}\text { Maior que } \\
10 \text { até } 20 \\
\text { SM }\end{array}$} & Não cotistas & 0,4 & 0,3 & 45,2 & 46,9 & 7,1 & 0,0 \\
\hline & Cotistas & 0,0 & 0,0 & 26,2 & 59,8 & 14,0 & 0,0 \\
\hline & $\%$ por etnia & 0,4 & 0,3 & 43,6 & 48,0 & 7,7 & 0,0 \\
\hline \multirow{3}{*}{$\begin{array}{c}\text { Maior que } \\
20 \text { até } 40 \\
\text { SM }\end{array}$} & Não cotistas & 1,0 & 0,4 & 56,6 & 37,9 & 4,0 & 0,0 \\
\hline & Cotistas & 0,0 & 0,0 & 13,6 & 72,7 & 13,6 & 0,0 \\
\hline & $\%$ por etnia & 1,0 & 0,4 & 54,7 & 39,5 & 4,4 & 1,0 \\
\hline \multirow{3}{*}{$\begin{array}{c}\text { Maior que } \\
40 \mathrm{SM}\end{array}$} & Não cotistas & 0,0 & 0,0 & 63,0 & 35,8 & 1,2 & 0,0 \\
\hline & Cotistas & 0,0 & 0,0 & 50,0 & 50,0 & 0,0 & 0,0 \\
\hline & \% por etnia & 0,0 & 0,0 & 62,8 & 36,0 & 1,2 & 0,0 \\
\hline \multirow{3}{*}{ Total } & Não cotistas & 0,3 & 0,6 & 31,8 & 50,3 & 16,9 & 0,0 \\
\hline & Cotistas & 0,0 & 2,1 & 8,0 & 53,5 & 36,1 & 0,2 \\
\hline & \%Total por etnia & 0,2 & 1,2 & 22,8 & 51,5 & 24,2 & 0,1 \\
\hline
\end{tabular}

Fonte: Elaboração própria com dados da UFBA (2013)

Observa-se que existe uma concentração de estudantes que se declararam preto para as duas faixas de renda mais baixas e este percentual tende a diminuir à medida que as faixas de renda aumentam. Do mesmo modo, os estudantes que 
declararam etnia "outro" são maiores nas duas faixas de renda maior e tendem a diminuir quando as faixas de renda diminuem.

Considerando a distribuição dos estudantes por faixa de renda e etnia, notase que os que se declararam pardo apresentam maior participação em todas as faixas de renda, exceto nas faixas de renda entre 20 até 40 salários mínimos e na maior que 40 salários mínimos, em que os declarados tiveram maior percentual. Interessante observar que à medida que aumenta a faixa de renda, aumenta a participação de cotistas e não cotistas pardos.

Com relação aos estudantes que se declararam preto, nota-se que a participação dessa etnia se reduz à medida que aumenta a faixa de renda, para ambas as categorias de seleção, ao ponto de não ter cotista preto com renda familiar acima de 40 salários mínimos. Com relação aos que se declaram na etnia, observa-se comportamento inverso à etnia preto: maior participação conforme aumenta a faixa de renda para ambas as categorias. Interessante notar que na faixa de renda acima de 40 salários mínimos $62,8 \%$ dos estudantes se declararam da etnia outros.

A Tabela 10 informa o coeficiente de rendimento médio por número de semestres cursados para as duas categorias de ingresso. Tem-se que, em média, os estudantes cotistas têm coeficiente de rendimento inferior ao dos não cotistas em todo o período. Porém, para as duas categorias, o desempenho dos estudantes aumenta à medida que avançam no curso. No geral, as diferenças nos coeficientes médios entre as categorias de ingresso são inferiores a 1,0 ponto e, em média, a diferença entre os CRs é de 0,3 pontos. Interessante também notar que o desvio padrão de ambas as categorias está em torno de 2,0 pontos e que a cada semestre seus valores são bastante próximos.

Tabela 10: Coeficiente de rendimento médio por número de semestres cursados e categoria de ingresso

\begin{tabular}{c|c|c|c|c|c|c|c}
\hline Categoria & $\begin{array}{c}\text { Semestres } \\
\text { cursado }\end{array}$ & $\begin{array}{c}\text { CR } \\
\text { médio }\end{array}$ & $\begin{array}{c}\text { Desvio } \\
\text { padrão }\end{array}$ & Categoria & $\begin{array}{c}\text { Semestres } \\
\text { cursado }\end{array}$ & $\begin{array}{c}\text { CR } \\
\text { médio }\end{array}$ & $\begin{array}{c}\text { Desvio } \\
\text { padrão }\end{array}$ \\
\hline & 1 & 5,3 & 2,7 & & 1 & 5,1 & 2,8 \\
Não cotistan & 2 & 5,9 & 2,3 & & 2 & 5,8 & 2,0 \\
& 3 & 6,0 & 2,1 & & 3 & 5,7 & 2,0 \\
& 5 & 6,2 & 1,9 & Cotista & 4 & 5,8 & 1,9 \\
& 5 & 6,7 & 1,7 & & 5 & 5,9 & 1,9 \\
\cline { 2 - 4 } & 6 & 6,7 & 1,7 & & 6 & 6,2 & 1,7 \\
\hline
\end{tabular}

Fonte: Elaboração própria com dados da UFBA (2013) 
Os resultados apresentados nessa seção apontam para existência de diferenciais de desempenho contra os cotistas, tanto em relação ao escore final do vestibular, quanto ao coeficiente de desempenho após a entrada na universidade. As lacunas educacionais, decorrentes das disparidades sociais e educacionais anteriores ao ingresso na universidade certamente refletem-se no desempenho destes estudantes dentro da universidade, mas talvez não de forma definitiva, haja vista que estes diferenciais não são tão acentuados ao longo do período. Medidas de assistência estudantil e permanência são de fundamental importância para permitir que alunos desprivilegiados possam suplantar suas dificuldades e desenvolver ao longo de seu curso.

\section{2 metodologia}

O método de investigação utilizado para estimar o impacto das cotas sobre a nota média semestral será o modelo dos Mínimos Quadrados Ordinários (MQO). De acordo com Wooldridge (2012), o método MQO consiste em encontrar as estimativas que minimizem a soma dos quadrados dos resíduos. Considerando a seguinte equação:

$$
y_{i}=\beta_{o}+\beta_{i} x_{1}+\beta_{2} x_{2}+\cdots+\beta_{k} x_{k}+u
$$

Em que $\beta_{o}$ é chamado parâmetro de intercepto ou coeficiente linear; $\beta_{i}$ é o parâmetro coeficiente angular; e $\mu$ o é o termo de erro.

E a mesma equação estimada:

$$
\hat{y}=\widehat{\beta_{o}}+\widehat{\beta_{1}}+\widehat{\beta_{2}}+\cdots+\widehat{\beta_{k}}
$$

O resíduo para a observação $i$ é a diferença entre o valor verdadeiro de $y_{i}$ e seu valor estimado $\left(\widehat{y}_{l}\right)$ :

$$
\hat{u}=y_{i}-\widehat{y}_{l}
$$

As estimativas de MQO são escolhidas para que a soma dos quadrados dos resíduos sejam mínimas:

$$
\sum_{i=1}^{n}\left(y_{i}-\widehat{\beta_{o}}+\widehat{\beta_{1}}+\widehat{\beta_{2}}+\cdots+\widehat{\beta_{k}}\right)
$$

As estimativas possuem algumas propriedades ótimas contidas no Teorema de Gauss-Markov. Esse justifica o uso do método dos mínimos quadrados em relação a outros estimadores possíveis. São cinco as hipóteses de Gauss-Markov. Hipótese 1: Linear em parâmetros. A variável dependente, y, relaciona-se com a variável independente, x, e com o termo de erro, u; Hipótese 2: Amostragem aleatória. Uma amostra de $n$ observações; Hipótese 3: Colinearidade imperfeita. Nenhuma das variáveis independentes é constante na amostra; Hipótese 4: Média condicional zero. O termo de erro tem valor igual à zero para quaisquer valores das variáveis independentes; Hipótese 5: Homocedasticidade. $\mathrm{O}$ erro tem a mesma variância para quaisquer valores das 
variáveis explicativas. Sob as hipóteses de Gauss-Markov, os estimadores de MQO são os melhores estimadores lineares não viesados (WOOLDRIDGE, 2012).

Para analisar o efeito de ser cotista na nota média semestral, utilizou-se o seguinte modelo:

\section{$\mathrm{CR}=\mathrm{f}$ (cotas,numsemestres,escfinal,feminino,doutorado, renda5sm,filhos)}

A variável CR representa o desempenho acadêmico, cotas é uma dummy, em que ser cotista é igual a um e não ser cotista é igual zero. Além dessas variáveis foram utilizadas outras como variáveis de controle, tais como: número de semestre, que indica os semestres cursados; escore final, o qual representa o escore final do vestibular; feminino, que é uma dummy que se o valor for igual a um representa gênero feminino e, se valor igual à zero é gênero masculino; doutorado, que indica a quantidade de doutores na universidade; renda de cinco salários mínimos, que também é uma dummy, em que se a renda familiar dos estudantes é acima de cinco salários mínimos assume valor igual a um e, se abaixo, assume valor zero; filhos é outra dummy, em que se valor igual a um, o estudante tem filho, e se valor zero não tem. A Tabela 11 resume as descrições de todas as variáveis utilizadas na estimação.

Tabela 11: Descrição das variáveis

\begin{tabular}{c|c|c|c|c|c|c}
\hline Variáveis & Descrição & $\begin{array}{c}\mathrm{N}^{\mathbf{0}} \\
\text { Observações }\end{array}$ & Média & $\begin{array}{c}\text { Desvio } \\
\text { padrão }\end{array}$ & Min & Max \\
\hline Escfinal & $\begin{array}{c}\text { Coeficiente de } \\
\text { Rendimento }\end{array}$ & 13.367 & 5,95 & 2,160192 & 0 & 9,7 \\
\hline Idade & $\begin{array}{c}\text { Escore final } \\
\text { Idade de ingresso } \\
\text { na Universidade }\end{array}$ & 13.354 & 21,51 & 6,452 & 1 & 67 \\
\hline Feminino & $\begin{array}{c}\text { Se gênero feminino, } \\
\text { feminino }=1\end{array}$ & 13.367 & 0,54 & 0,498 & 0 & 1 \\
\hline Cotas & $\begin{array}{c}\text { Se cotista, } \\
\text { cotas }=1\end{array}$ & 13.367 & 0,38 & 0,485 & 0 & 1 \\
\hline Doutorado & $\begin{array}{c}\text { Se doutor, } \\
\text { doutorado=1 }\end{array}$ & 13.367 & 0,53 & 0,268 & 0 & 1 \\
\hline renda5sm & $\begin{array}{c}\text { Se tem renda maior } \\
\text { que } 5 \text { SM, ren- } \\
\text { da5sm=1 }\end{array}$ & 13.367 & 0,35 & 0,478 & 0 & 1 \\
\hline Numsemetres & $\begin{array}{c}\text { Número de } \\
\text { semestre }\end{array}$ & 13.367 & 3,46 & 1,687 & 1 & 6 \\
\hline
\end{tabular}

Fonte: Elaboração própria com dados da UFBA (2013) 


\subsection{Resultados}

Para averiguar a existência de um possível diferencial de desempenho entre os alunos cotistas e não cotistas, foi realizado um teste de médias por categorias, conforme apresentado na Tabela 12. Os resultados preliminares, baseados no coeficiente de rendimento, indicam que existe diferença de notas entre cotistas e não cotistas. Recorre-se ao teste $t$ para testar a hipótese nula que não existe diferença na nota média dos não cotistas e cotistas, com nível de significância de $1 \%$ apresentando os seguintes resultados para os três anos:

Tabela 12: Teste $t$ da nota média semestral para cotistas e não cotista

\begin{tabular}{|c|c|c|c|c|c|c|}
\hline Categoria & Observações & Média & $\begin{array}{l}\text { Erro } \\
\text { Padrão }\end{array}$ & $\begin{array}{l}\text { Desvio } \\
\text { Padrão }\end{array}$ & \multicolumn{2}{|c|}{$\begin{array}{c}{[95 \% \text { Intervalo de }} \\
\text { Confiança] }\end{array}$} \\
\hline Não cotista & 8301 & 6.04785 & .0243025 & 2.214197 & 6.000211 & 6.095489 \\
\hline Cotista & 5066 & 5.794631 & .0289315 & 2.059223 & 5.737913 & 5.851349 \\
\hline Combinado & 13367 & 5.951881 & .0186842 & 2.160192 & 5.915258 & 5.988505 \\
\hline Diferença & & .2532188 & .0384525 & & .1778465 & .3285911 \\
\hline \multicolumn{7}{|c|}{ Diferença $=$ média $($ não cotista $)-$ média (cotista) } \\
\hline \multicolumn{7}{|c|}{ Ho: diferença $<0$ Ha: diferença $=0$} \\
\hline \multicolumn{2}{|c|}{$\operatorname{Pr}(T<t)=1.0000$} & \multicolumn{2}{|c|}{$\operatorname{Pr}(|\mathrm{T}|>|\mathrm{t}|)=0.0000$} & \multicolumn{3}{|c|}{$\operatorname{Pr}(\mathrm{T}>\mathrm{t})=0.0000$} \\
\hline
\end{tabular}

Fonte: Elaboração própria com dados da UFBA (2013)

Para um teste bicaudal com nível de significância de $1 \%$ e graus de liberdade grande (>120), o valor crítico é de 2,576. Isto indica que a hipótese nula será rejeitada se a estatística $t$ for maior que o valor crítico. $\mathrm{Na}$ amostra analisada, a estatística t é 6.5852, logo a diferença de nota semestral entre os dois grupos é estatisticamente significante ao nível de $1 \%$. Entretanto, quando se faz a análise por área de conhecimento, o teste $t$ apresenta o mesmo resultado apenas na área I e II, enquanto que para as áreas III, IV e V a estatística t é menor que o valor crítico, desse modo não é possível rejeitar a hipótese nula no nível de significância de 1\%, o que implica que só existe diferença de desempenho entre as categorias de seleção para análise conjunta e na analise por áreas de conhecimento apenas na área I.

Os resultados obtidos com a estimação de ser cotista sobre o coeficiente de rendimento de cada semestre em comparação com os alunos não cotistas através do método dos Mínimos Quadrados Ordinários com os dados agrupados pelo número de matrícula são apresentados na Tabela 13. 
Tabela 13: Resultado das Estimações

\begin{tabular}{|c|c|c|c|c|c|c|}
\hline \multicolumn{7}{|c|}{ Variável dependente: Coeficiente de Rendimento } \\
\hline $\begin{array}{c}\text { Variáveis } \\
\text { independentes }\end{array}$ & Geral & Área I & Área II & Área III & Área IV & Área V \\
\hline \multirow{2}{*}{ Cotas } & $-0.260^{* \cdots *}$ & -0.433 & $-0.299^{* \cdots *}$ & $-0.246^{m * n}$ & -0.0470 & 0.374 \\
\hline & $(-6.74)$ & $(-5.89)$ & $(-4.87)$ & $(-3.65)$ & $(-0.27)$ & $(1.93)$ \\
\hline \multirow{2}{*}{ Numsemestres } & $0.141^{\ldots * *}$ & $0.0442^{*}$ & $0.138^{* \ldots * 3}$ & $0.189^{* \ldots *}$ & $0.410^{* \ldots *}$ & $0.167^{*}$ \\
\hline & $(12.75)$ & $(2.18)$ & $(7.68)$ & $(9.70)$ & $(8.00)$ & $(3.15)$ \\
\hline \multirow{2}{*}{ Escfinal } & $0.000187^{* * *}$ & $0.000221^{*}$ & 0.000178 & $0.000161^{* \ldots m}$ & $0.000256^{* \ldots *}$ & $0.000108^{*}$ \\
\hline & $(29.92)$ & $(19.48)$ & (18.54) & $(13.42)$ & $(5.07)$ & $(2.82)$ \\
\hline \multirow{2}{*}{ Feminino } & $0.879^{* \ldots * *}$ & $0.642^{* * * *}$ & $0.525^{\ldots * \ldots}$ & $0.987^{* 0 *}$ & $0.573^{* * * *}$ & $0.419^{*}$ \\
\hline & $(24.98)$ & $(9.41)$ & $(8.49)$ & $(15.65)$ & $(3.45)$ & $(2.45)$ \\
\hline \multirow{2}{*}{ Doutorado } & $0.168^{* *}$ & $0.546^{* * *}$ & -0.424 & 0.0377 & -0.182 & 0.348 \\
\hline & $(2.58)$ & $(4.22)$ & $(-3.38)$ & $(0.36)$ & $(-0.64)$ & $(1.12)$ \\
\hline \multirow{2}{*}{ renda $5 \mathrm{sm}$} & $0.190^{* * *}$ & -0.00757 & 0.0240 & $0.302^{* \ldots}$ & $0.411^{*}$ & 0.289 \\
\hline & $(4.66)$ & $(-0.10)$ & $(0.37)$ & $(4.14)$ & $(2.38)$ & $(1.47)$ \\
\hline \multirow{2}{*}{ Filhos } & $-0.757^{* * *}$ & $-1.601^{* \ldots *}$ & $-0.525^{\ldots}$ & $-0.617^{* \%}$ & -0.340 & $0.773^{* *}$ \\
\hline & $(-9.51)$ & $(-9.11)$ & $(-2.86)$ & $(-4.91)$ & $(-1.37)$ & $(-2.65)$ \\
\hline \multirow{2}{*}{ _cons } & $2.610^{* * *}$ & $2.082^{* * *}$ & $3.521^{* * a}$ & $3.038^{* * * 3}$ & 0.813 & $3.740^{* \ldots}$ \\
\hline & $(27.77)$ & $(12.48)$ & $(23.70)$ & $(17.28)$ & $(1.23)$ & $(5.41)$ \\
\hline $\mathrm{N}$ & 13367 & 3714 & 3513 & 4606 & 815 & 719 \\
\hline R-sq & 0.1368 & 0.1760 & 0.1574 & 0.1286 & 0.1441 & 0.0493 \\
\hline $\mathrm{F}$ & 302.43 & 113.12 & 93.54 & 96.92 & 19.41 & 5.27 \\
\hline
\end{tabular}

Estatística t em parênteses

$* \mathrm{p}<0.05, * \mathrm{p}<0.01, * * \mathrm{p}<0.001$

Fonte: Elaboração própria com dados da UFBA (2013)

O sinal da estimativa do coeficiente de inclinação de cotas ratifica o observado na descrição dos dados da seção anterior. Mantendo as demais variáveis fixas, a variação em cotas indica que o aluno cotista tem sua nota reduzida em $0.260 \mathrm{em}$ relação a um aluno não cotista. Dessa forma é possível perceber que os cotistas tem rendimento inferior aos não cotistas mesmo que o escore final de classificação no vestibular (escfinal) tenha sido igual para ambas as categorias.

Analisando por área, a variável cotas, não é estatisticamente significante para as áreas IV e V. A estatística descritiva já mostrava que a diferença de desempenho é vista claramente para a área I e se reduz para área II e III e que em relação às áreas 
IV e $\mathrm{V}$, os cotistas demonstravam desempenhos melhores que os não cotistas. Os cursos que compõe as áreas I, II, III são de maior concorrência e, particularmente os que englobam as duas primeiras áreas, exigem um bom conhecimento em matemática e física, as quais são disciplinas que são tidas como não são oferecidas de forma satisfatória no ensino público

A diferença apontada na regressão sem separação por área pode ser revertida através do controle das variáveis que afetam o desempenho dos cotistas, considerando que estes têm oportunidades distintas e estão mais propensos à vulnerabilidade socioeconômica que os não cotistas. Este artigo não considerou medidas de permanência na análise, porém, o Plano Nacional de Assistência Estudantil (Pnaes) oferece um conjunto de medidas que objetivam apoiar a permanência de estudantes de baixa renda e contribuir para um bom desempenho, em que cada universidade tem autonomia para acrescentar os critérios de acordo com a sua realidade para selecionar os beneficiados.

Conforme dito anteriormente, a UFBA conta com a Pró-Reitoria de Ações Afirmativas e Assistência Estudantil (PROAE) para construção e execução das ações e medidas de permanência e assistência estudantil. Nesse sentido, a Universidade oferece um amplo conjunto de ações complementares que visam propiciar aos discentes cotistas (e de baixa renda) condições para lograrem um bom desempenho ao longo da graduação.

A variável numsemestres mostra que à medida que o aluno avança nos semestres o coeficiente de rendimento aumenta em, aproximadamente, 0.141 décimos em ambas as categorias de seleção. Esse fato é interessante, pois atividades extracurriculares, como estágios, necessárias para a formação complementar do aluno, poderiam implicar em diminuição do coeficiente de rendimento no decorrer dos cursos. Entretanto, a possibilidade de escolher as disciplinas da grade semestral e as próprias características das disciplinas que tendem a sair da forma geral para matérias mais direcionadas ao curso escolhido pode ser uma das possíveis explicações que já tinham sido sinalizadas pela estatística descritiva.

O coeficiente da variável filhos mostra que ter filhos diminui expressivamente o coeficiente de rendimento. Essa diminuição é plausível, pois estudantes com filhos tem tempo disponível menor que os estudantes sem filhos, podendo implicar em um esforço maior que nem sempre é possível para esses estudantes.

O coeficiente da variável escfinal (0.000187) indica que o escore final médio do vestibular tem participação irrisória sobre a nota média semestral do estudante. Significando que, mantendo as demais variáveis constantes, os alunos que tiveram escore final alto não terão necessariamente coeficiente de rendimento maiores, ratificando o que foi visto na seção anterior na análise do escore do vestibular e coeficiente de rendimento por gênero, em que o gênero masculino apresentava maior média de escore final, no entanto, o gênero feminino apresentava maior coeficiente de rendimento. 
Em relação à questão do gênero, a variável feminino é uma variável dummy e o coeficiente estimado mensura a diferença ceteris paribus entre os dois gêneros (feminino e masculino). A variável tem coeficiente positivo e indica que os alunos do gênero feminino têm nota média semestral $87,9 \%$ maior que os do gênero masculino. Como dito anteriormente, a análise descritiva já havia sinalizado que apesar dos homens apresentaram escore médio final do vestibular maior isto não é mantido com o ingresso na universidade.

O coeficiente positivo da variável doutorado é interessante, pois indica que professores com doutorado influenciam positivamente na nota do aluno. Ter professores com doutorado contribui para as maiores notas dos alunos cotistas e não cotistas. Este resultado ratifica uma das implicações do modelo de Bishop (2006) em que sinalizava a relação positiva da qualidade do professor com o esforço do aluno.

A variável renda $5 m$ mostra que os estudantes com renda familiar maior que cinco salários mínimos têm notas médias semestrais maiores que aqueles com renda menor. Uma das possíveis causas é que os estudantes de menor renda familiar podem ter que trabalhar para completar os rendimentos da família, interferindo diretamente no tempo dedicado aos estudos.

$\mathrm{Na}$ análise por áreas de conhecimento, as estatísticas apresentam resultados diferentes da análise conjunta. Paras áreas I e II ser cotista reduz a nota média em $43,3 \%$ e $29,9 \%$ respectivamente, estas são as áreas que apresentam maior diferencial de notas entre cotistas e não cotistas. No entanto, para as áreas IV e V, a variável cotas não foi estatisticamente significante, o que implica que a hipótese de existência de diferencial de desempenho entre as duas categorias é rejeitada. É importante ressaltar que a não significância estatística não impõe que as medias entre as duas categorias de seleção são iguais, apenas que a amostra não forneceu evidencia suficiente para rejeitar a hipótese que existe diferença.

A variável doutorado também não é estatisticamente significante para as áreas III, IV e V. Como os dados são agregados e cada área de conhecimento tem cursos com características particulares, às razões para os quais professores mais qualificados apresentarem impacto negativo na nota média semestral requer investigações mais aprofundadas. Já para as variáveis numsemestres, escfinal, feminino e filbos apresentam comportamento por área de conhecimento semelhante ao comportamento na análise conjunta.

Os resultados globais mostram que mesmo após o controle das demais variáveis o cotista apresenta desempenho inferior ao do não cotista na universidade. No início do curso, o estudante tem melhor desempenho e este tende a diminuir ao longo da vida acadêmica para ambas as categorias. Estudantes com filhos têm notas médias menores que aqueles que não têm e as mulheres apresentam melhores médias. O escore do vestibular não tem muita influencia sobre a nota média enquanto ter renda familiar maior do que cinco salários mínimos e ter professores com doutorado também influência positivamente o desempenho dos alunos. 


\section{Considerações Finais}

A crescente literatura teórica e empírica sobre as ações afirmativas na educação evidencia a relevância que a temática assume para a sociedade. A sanção da Lei de Cotas em 2012, que determina que 50\% das matrículas das universidades e institutos federais sejam destinadas a alunos que frequentaram o ensino médio em colégios públicos, contribui ainda mais para o debate sobre as ações afirmativas, sobretudo sobre a eficácia e de que forma os incentivos criados por ela afetam o desempenho do estudante, a retenção e evasão.

As ações afirmativas podem ser compreendidas como um conjunto de medidas que buscam promover uma igualdade de oportunidade para determinados grupos que tenham sido excluídos sócio e/ou economicamente. $\mathrm{Na}$ educação, as ações afirmativas desempenham um papel bastante importante, principalmente quando se considera a importância da educação para o crescimento e desenvolvimento econômico e o fato da formação do capital humano de uma sociedade e o desenvolvimento tecnológico ocorrerem principalmente dentro das universidades, pela qualificação e treinamento dos indivíduos, a ação afirmativa permite a uma parcela da população, antes excluída desse processo de formação do capital humano, tenha condições de se qualificar e retribuir para a sociedade.

Esse artigo analisou o impacto das ações afirmativas na Universidade Federal da Bahia por meio da verificação se existe diferencial de desempenho entre alunos beneficiários do sistema de reserva de vagas e os demais estudantes por grandes áreas de conhecimento nos anos de 2010, 2011 e 2012. Os resultados encontrados pela regressão indicam que os estudantes cotistas tem nota média menor que os não cotistas quando se analisa o conjunto total de áreas de conhecimento. As áreas I e II são as que mostram diferenciais de desempenho mais acentuados, possivelmente devido ao conhecimento necessário que os cursos englobados exigem, como matemática e física, disciplinas que são supostas serem as de maiores dificuldades para os estudantes oriundos de escolas públicas. Entretanto, nas áreas IV- Letras e V- Artes, os cotistas apresentam melhores desempenhos, o qual pode estar atrelado ao caráter avaliativo dos cursos que compõe a área e o fato da habilidade individual ser mais relevante na determinação do desempenho.

Outro aspecto observado foi a média do escore final do vestibular dos estudantes que, em geral, são maiores para os não cotistas, porém em 2012 apresentou uma inversão, tendo os cotistas melhores desempenhos tanto no global para o ano, quanto por área de conhecimento. Uma das possíveis causas é que as escolas públicas englobam os institutos federais e colégios militares conhecidos pela qualidade do ensino e estes podem estar afetando a média, no entanto, para conclusões consistentes e mais acuradas pretende-se futuramente averiguar a presença de um possível outlier neste ano ou se este comportamento divergente dos outros dois anos representa a diminuição do gap na formação escolar entre cotistas e não cotistas. 
Os resultados sugerem que o diferencial contra ao desempenho dos estudantes cotistas, relativamente aos demais não cotistas, parece anteceder à própria entrada na Universidade. Considerando que o processo educacional é inerentemente hierárquico, ou seja, etapas precisam ser cumpridas com sucesso para que ocorra o avanço, se o ensino básico, e mais especificamente o ensino médio, apresenta baixa qualidade, certamente isto se refletirá no desempenho dos alunos na universidade. Esse parece ser o caso principalmente das áreas de exatas, por exemplo, em que a hierarquia do processo mostra-se clara na organização das disciplinas.

A análise proposta por esse artigo sugere que a UFBA está conseguindo controlar as assimetrias prévias da formação educacional entre os cotistas e não cotistas e as ações afirmativas realmente estão conseguindo alcançar o seu objetivo. Todavia, para afirmar o sucesso da política é necessário avaliar não somente em termos de desempenho do aluno como também o que está ocorrendo após a conclusão e a inserção para o mercado de trabalho dos beneficiados. Ademais, ainda que a política de ação afirmativa deva ter um caráter temporal, seus resultados não podem ser vistos completamente de forma imediata, pelo contrário, efeitos intergeracionais são esperados, o que leva normalmente décadas para poderem ser observados. Como afirmado por Sowell (p.7, 2004), a mudança na condição socioeconômica destes grupos minoritários na educação superior não pode acontecer sem mudanças estruturais que lhe permita, enquanto cidadãos, iguais condições de exercer sua cidadania, ou seja, oportunidades iguais para todos.

\section{Referências}

ALMEIDA FILHO, Naomar de Almeida; MARINHO, Maerbal Bittencourt; CARVALHO, Manoel José de; e SANTOS, Jocélio Teles dos. Ações Afirmativas $\mathrm{Na}$ Universidade Pública: O caso da UFBA. Centro de Estudos Afro-Orientais da UFBA. Salvador, Bahia, 2005.

ARCIDIACONO, Peter; AUCEJO, Esteban M.; FANG, Hanming; e SPENNER, Kenneth L. Does Affirmative Action Lead to Mismatch? A new test and evidence. Quantitative Economics 2 (2011), 303-333. crossrefhttps://doi.org/10.3982/QE83

BARNES, Katherine. Is Affirmative Action Responsible For The Achievement Gap Between Black And White Law Students? A Correction, A Lesson, And An Update. Northwestern University School Of Law. Northwestern University Law Review. Printed in USA. Vol. 105, nº 2011.

BERTRAND, Marianne; HANNA, Rema; e MULLAINATHAN, Sendhil. Affirmative Action In Education: Evidence from engineering college admissions in India. Journal of Public Economics 94 (2010), 16-29. crossrefhttps://doi.org/10.1016/j. jpubeco.2009.11.003 
BISHOP, John. Drinking from the Fountain of Knowledge: Student Incentive to Study and Learn: Externalities, Information Problems and Peer Pressure. 2006. Disponível em <http://digitalcommons.ilr.cornell.edu/cgi/viewcontent.cgi?article=1018\&co ntext $=$ cahrswp $>$. Acesso em 27 de novembro de 2013.

FANG, Hanming; e MORO, Andrea. Theories of Statistical Discrimination and Affirmative Action: A Survey. Handbook of Social Economics, Volume 1A, 2011. Elsevier B.V.

FRANCIS, Andrew M.; TANNURI-PIANTO, Maria. Using Brazil's Racial Continuum to Examine The Short-Term Effects of Affirmative Action in Higher Education. Journal of Human Resources, Volume 47, Number 3, Summer 2012, pp. 754784.

FRYER, Roland G.; eLOURY, Glenn C.Affirmative Action and Its Mythology. American Economic Association. The Journal of Economic Perspectives, vol. 19, n. 3 (Summer, 2005), pp. 147-162. crossrefhttps://doi.org/10.1257/089533005774357888

GARCES, Liliana M. The Impact of Affirmative Action Bans in Graduate Education. George Washington University, University of Michigan, July, 2012.

GRUPO DE ESTUDOS MULTIDISCIPLINAR DA AÇÃO AFIRMATIVA (GEMAA). Disponível em: < http://gemaa.iesp.uerj.br/>. Acesso em: 05 de janeiro de 2014.

HERINGER, R.; FERREIRA, R. Análise das principais políticas de inclusão de estudantes negros no ensino superior no Brasil: período 2001-2008. 2009.

HOLZER, Harry, e NEUMARK, David. Assessing Affirmative Action. American Economic Association. Journal of Economic Literature, vol. 38, n. 3 (Sept., 2000), pp. 483-568.

KRISHNA, Kala; e TARASOV, Alexander. Affirmative Action: One Size Does Not Fit All. National Bureau of Economic Research, 1050 Massachusetts Avenue, Cambridge, MA 02138, October, 2013.

LORDÊLO, J. A. C. Perfil, Desempenho Escolar, Exclusão e Inclusão no Curso de Administração da UFBA: locus para a ação afirmativa? Diálogos Possíveis (FSBA), Salvador, v. 2, p. 199-217, 2004.

MOEHLECKE, S. Ação afirmativa: história e debates no Brasil. Cadernos de Pesquisa, São Paulo, n. 117, novembro/2002, p. 4.

PERREIRA, J. I. R. Análise do impacto da implantação das cotas na nota ENADE 
2008. 2013. 68f. Dissertação (Mestrado em Economia) - Faculdade de Economia, UFPR, Paraná, 2013.

QUEIROZ, Delcele M.; SANTOS, Jocélio T. dos. Vestibular com cotas: análise em uma instituição pública federal. Revista USP, São Paulo, n. 68, p. 58-75, 2006.

SANDER, Richard H. A Systemic Analysis Of Affirmative Action In American Law Schools. Stanford Law Review. Vol. 57-367, November 2004.

SANTOS, Jocélio Teles dos. Ações Afirmativas e Educação Superior no Brasil: um balanço crítico da produção. R. Bras. Est. Pedag., Brasília, v. 93, n. 234, [número especial], p. 401-422, maio/ago. 2012.

SILVA FILHO, Penildon, e CUNHA, Eudes Oliveira. As politicas de ações afirmativas na educação superior no Brasil sob a ótica da equidade. Universidade Federal da Bahia, 2013.

SU, X. Education Hierarchy, Within-Group Competition and Affirmative Action. Working Paper. 2005. Disponível em: $<$ http://papers.ssrn.com/sol3/papers. cfm?abstract_id=781104>. Acesso em 27 de novembro de 2013.

UFBA, Universidade Federal da Bahia. Resolução 01/04. Ano de 2004. Disponível em: < http://www.vestibular.ufba.br/resolucoes.htm>. Acesso em: 27 de novembro de 2013.

VELLOSO, Jacques R. Cotistas e não cotistas: Rendimento de alunos da Universidade de Brasília. Cadernos de Pesquisa (Fundação Carlos Chagas. Impresso), v. 39, p. 621-644, 2009.

WOOLDRIDGE, Jeffrey M. Introdução à Econometria: uma abordagem moderna. São Paulo: Cengage Learning, 2012. 


\section{INSTRUCTIONS FOR CONTRIBUTORS}

Economia Ensaios is the Journal of the Economics Institute at Federal University of Uberlândia, Brazil (Universidade Federal de Uberlândia). The Journal adopts a pluralist orientation and publishes Papers, Review Articles, Book Reviews, Notes and Comments and others unpublished contributions in all areas of economics and allied disciplines.

- Submissions of a paper to the Economia Ensaios will be taken to imply that it has not been previously published. In special cases a simultaneous publication in foreing journal will be accepted.

- All the works submitted to the Journal are peer-reviewed (double-blind review) by two members of the Editorial Bord or by specialists ad hoc.

- Send na eletronic version to ecoensaios@ufu.br.

- An abstract of no longer than 100 words, a list of key-words and the JEL classification (Journal of Economic Literature Classification System) should accompany the paper.

- The originals will be considered definitive, and, in case of their approval for publication, proofs will not be sent to authors.

- Submission of a manuscript implies commitment to publish in the Journal. No copyrights will be paid.

ECONOMIA ENSAIOS will always reply to the authors. In case of approval, changes may be suggested.

Editorial correspondence should be sent to:

Revista Economia Ensaios

Universidade Federal de Uberlândia

Instituto de Economia

Av João Naves de Ávila, 2121

Campus Santa Mônica, Bloco J, sala 249

38408-144 - Uberlândia, MG, Brazil

Fone: 5534 3239-4315

e-mail: ecoensaios@ufu.br

www.ppge.ie.ufu.br 



\section{NORMAS PARA A SUBMISSÃO DE TRABALHOS}

A Revista Economia Ensaios é editada pelo Instituto de Economia da Universidade Federal de Uberlândia. A Revista adota uma orientação pluralista e publica Artigos, Artigos-resenha, Resenhas de Livros, Notas e Comentários e outras contribuições inéditas em economia teórica e aplicada e áreas afins.

- Os trabalhos submetidos à Revista Economia Ensaios devem ser originais. Em casos especiais, será aceita a publicação simultânea em revista estrangeira.

- Todos os trabalhos submetidos são avaliados por dois pareceristas, membros do Conselho Editorial ou especialistas indicados ad hoc, preservando-se o anonimato dos autores e pareceristas (double-blind review).

- Os artigos e demais contribuições devem ser enviados em versão digital para o endereço eletrônico da revista: ecoensaios@ufu.br.

- Todos os artigos enviados à Revista devem ser acompanhados de resumo (máximo de 100 palavras) em português e em inglês, lista de palavras-chave, também em português e em inglês, e classificação JEL (Journal of Economic Literature Classification System).

- Os originais apresentados serão considerados definitivos e, caso aprovados para publicação, as provas não serão submetidas à correção dos autores.

- A simples remessa de originais à Revista implica autorização para publicação. Não serão pagos direitos autorais.

- As referências bibliográficas completas, apresentadas em ordem alfabética, devem ser colocadas ao final do trabalho, em conformidade com as normas para apresentação de trabalhos técnico-científicos da ABNT - Associação Brasileira de Normas Técnicas.

A Revista Economia Ensaios compromete-se a dar sempre uma resposta para os autores. Em caso de aprovação, poderão ser sugeridas modificações.

Endereço para correspondência:

Revista Economia Ensaios

Universidade Federal de Uberlândia

Instituto de Economia

Av João Naves de Ávila, 2121

Campus Santa Mônica, Bloco J, sala 249

38408-144 - Uberlândia-MG

Fone: 5534 3239-4315

e-mail: ecoensaios@ufu.br

www.ppge.ie.ufu.br 
gráficaufu 